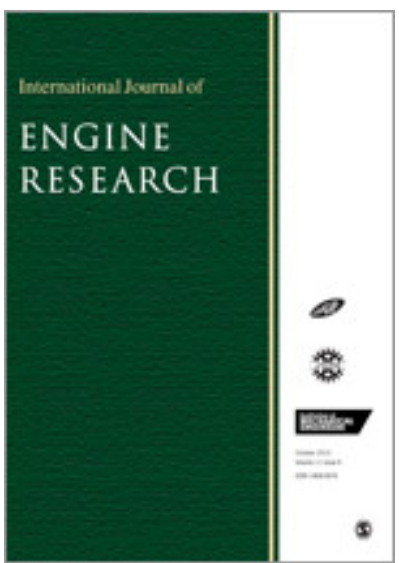

\title{
Novel approach for adaptive coefficient tuning for the simulation of evaporating high-speed sprays injected into a high temperature and pressure environment
}

\begin{tabular}{|c|c|}
\hline Journal: & International Journal of Engine Research \\
\hline Manuscript ID & IJER-19-0139.R1 \\
\hline Manuscript Type: & Standard Article \\
\hline $\begin{array}{r}\text { Date Submitted by the } \\
\text { Author: }\end{array}$ & 08-Aug-2019 \\
\hline Complete List of Authors: & $\begin{array}{l}\text { Nsikane, Daniel; University of Brighton, Advanced Engineering Center; } \\
\text { Ricardo plc, Ricardo Innovation } \\
\text { Vogiatzaki, Konstantina; University of Brighton } \\
\text { Morgan, Robert; University of Brighton, Advanced Engineering Center } \\
\text { Mustafa, Kenan; Ricardo plc, Ricardo Innovation } \\
\text { Ward, Andy; Ricardo plc, Ricardo Innovation } \\
\text { Winder, Nick; Ricardo plc, Ricardo Innovation }\end{array}$ \\
\hline Keywords: & $\begin{array}{l}\text { Design-of-Experiments, ECN Spray A, RANS, Diesel spray injection } \\
\text { simulations, Input parameter tabulation }\end{array}$ \\
\hline Abstract: & $\begin{array}{l}\text { Producing reliable in-cylinder simulations for quick turnaround engine } \\
\text { development for industrial purposes is a challenging task for modern } \\
\text { CFD, mostly because of the tuning effort required for the sub models } \\
\text { used in the various frameworks (RANS and LES). Tuning is required } \\
\text { because of the need of modern engines to operate under a wider range } \\
\text { of conditions and fuels. In this paper we suggest a novel methodology } \\
\text { based on automated simulation parameter optimisation that is capable of } \\
\text { delivering a priori a coefficient matrix for each operating condition. This } \\
\text { approach produces excellent results for multiple comparison metrics like } \\
\text { liquid and vapor penetration lengths, radial and axial mass fraction and } \\
\text { temperature distributions. In this paper we also show for the first time } \\
\text { that input model coefficients can potentially be linked to ambient } \\
\text { boundary conditions in a physically consistent manner. Changes in } \\
\text { injection pressure, charge pressure and charge density are considered. } \\
\text { This paves the way for the tabulation of the constants in order to } \\
\text { eliminate lengthy tuning iterations between operating conditions and } \\
\text { move towards adaptive simulations as the piston moves changing the in- }\end{array}$ \\
\hline
\end{tabular}


cylinder conditions. An additional discussion is performed for the validity range of existent models given that in the recent years there has been a shift towards more extreme thermodynamic conditions in the injection stage (reaching the limits of trans critical flows). Although in this work the framework was implemented in the RANS context because this is the tool of preference of digital engineering currently by automotive industries, the approach can be easily extended in LES.

\section{SCHOLARONE ${ }^{\mathrm{m}}$ \\ Manuscripts}




\title{
Novel approach for adaptive coefficient tuning for the
}

\author{
simulation of evaporating high-speed sprays injected
}

\section{into a high temperature and pressure environment}

\author{
D. M. Nsikane ${ }^{1,2}$, K. Vogiatzaki ${ }^{1}$, R. E. Morgan ${ }^{1}$, M. Heikal ${ }^{1}$, K. Mustafa ${ }^{2}$, A. Ward $^{2}$, N. \\ Winder
}

${ }^{1}$ Centre for Automotive Engineering, University of Brighton, Lewes Road, Brighton BN2 4GJ, United Kingdom

${ }^{2}$ Ricardo Innovations, STC, Old Shoreham Rd, Shoreham-by-Sea, BN43 5FG, United Kingdom

Corresponding Author: D. M. Nsikane ${ }^{1}$

Manuscript to be printed in colour

\begin{abstract}
Producing reliable in-cylinder simulations for quick turnaround engine development for industrial purposes is a challenging task for modern CFD, mostly because of the tuning effort required for the sub models used in the various frameworks (RANS and LES). Tuning is required because of the need of modern engines to operate under a wider range of conditions and fuels. In this paper
\end{abstract}


we suggest a novel methodology based on automated simulation parameter optimisation that is capable of delivering a priori a coefficient matrix for each operating condition. This approach produces excellent results for multiple comparison metrics like liquid and vapor penetration lengths, radial and axial mass fraction and temperature distributions. In this paper we also show for the first time that input model coefficients can potentially be linked to ambient boundary conditions in a physically consistent manner. Changes in injection pressure, charge pressure and charge density are considered. This paves the way for the tabulation of the constants in order to eliminate lengthy tuning iterations between operating conditions and move towards adaptive simulations as the piston moves changing the in-cylinder conditions. An additional discussion is performed for the validity range of existent models given that in the recent years there has been a shift towards more extreme thermodynamic conditions in the injection stage (reaching the limits of trans critical flows). Although in this work the framework was implemented in the RANS context because this is the tool of preference of digital engineering currently by automotive industries, the approach can be easily extended in LES.

Keywords: Design-of-Experiments, ECN Spray A, RANS, Diesel spray, Injection simulations 


\section{$1 \quad 1 \quad$ Introduction}

2 Digital product development, based on advanced numerical modelling, is progressively becoming an

3 integral part of the design of modern energy systems. Testing future combustion systems in a virtual

4 environment is a more time and cost-effective way of design optimisation in comparison to conventional

5 hardware-based methods. However, the success of the optimisation depends on the reliability of the

6 virtual tools which require rigorous validation to a wide range of operating conditions. For diesel

7 injection and combustion in Internal Combustion Engines (ICEs), this can be a challenging task due to

8 the large range of scales and phases involved in fuel injection dynamics. Simulating the full spray

9 injection, mixing, evaporation and combustion at thermodynamically extreme conditions (injection

10 pressures beyond $250 \mathrm{MPa}$ ) that modern systems operate in, is both a scientifically and computationally

11 challenging task.

12 Detailed physical calculations (such as Direct Numerical Simulation (DNS) and to some extent Large

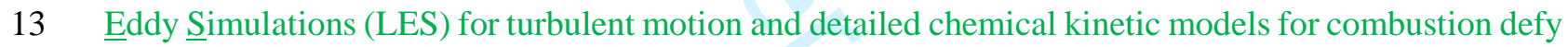

14 the purpose of using Computational Fluid Dynamics (CFD) as a time efficient virtual design tool for

15 commercial purposes. For engine developers, quick-turnaround simulations of global combustion

16 parameters such as heat release (and the associated pressure rise), spray penetration and lift-off length

17 (to guide bowl design to avoid wall impingement) and emission production at a range of operating

18 conditions are of paramount interest. Simulations which can capture characteristic trends against

19 operating conditions would allow faster engine mapping. Using methods that "ignore" some of the

20 scales of the problems under investigation (such as $\underline{\text { Reynolds- }}$ - veraged $\underline{\text { Navier-S}}$ tokes (RANS) and to

21 some extent LES for turbulent motion and tabulated or reduced chemical kinetic models for

22 combustion) can reduce the run time but introduce new uncertainties. These numerical models use a

23 range of parameters to encapsulate real physics or bridge "unknown" or "unresolved" processes.

24 Many experiments have been conducted in constant volume chambers. These have mostly been led by

25 researchers of the Sandia National Laboratories and contributors of the Engine Combustion Network

26 (ECN). The focus to date has been on turbulent spray flames under diesel-like combustion condition. 
The setup allows a high degree of optical access for advanced experimental diagnostics and wellcharacterised initial and boundary conditions for simulations, including detailed fuel injector characterisation (1-3). Their experiments showed the effects of operating conditions like charge pressures, densities, temperatures and injection pressures or fuel injection equipment specifications like nozzle orifice diameter on spray (4-9), jet (10-14), combustion (13-21) and emission (22-27) characteristics. In (4), Siebers outlines the effect of boundary conditions on liquid penetration. Liquid length is linearly dependent on orifice diameter and fuel temperature, independent of injection pressure, highly sensitive to gas densities \& temperatures. These results are confirmed by other researchers like $(6,7,28)$. A study by Pickett et al in (18) links the dependency of Ignition Delay (ID) to ambient gas densities, temperatures, oxygen concentrations and the fuel cetane number. Another study by Siebers et al in (16) and more recently by Benajes et al in (13) characterizes the response of flame lift-off to the above-mentioned operating conditions and fuel injection specifications.

Corresponding computational simulations were carried out by various groups using RANS approaches (29), coupled with conditional moment closure (CMC) (30, 31), transported probability density function (TPDF) (32-35) or flamelet-type models (36-38), or LES approaches (39-49). Among others, work by Bolla et al $(30)$ and Pei et al $(32,34)$ shows that while acceptable trends can be achieved for the bulk of the available experimental data without changing model input parameters, matching the results quantitatively is more difficult.

Expecting that a low-fidelity simulation setup can be tuned to one key point and then without adjustment predict another, conversely asserts that a range of changing thermodynamic conditions can be captured by simplified sub-models. This however is not always the case and our studies have shown that by accepting limitations to these simplified sub-models and adjusting tuning constants to the new environment, these inaccuracies may be addressed. The determination of which coefficients have a significant impact on certain performance measures of interest is difficult. Common single parameter swings are often incorrect and misleading due to the multivariable interaction on various responses. Literature showing the effect of isolated parameter swings can be found in (50-52). The problem with the "single parameter swing approach" is that it is not necessarily useful for future predictive engine 
54 simulations. If after such parameter swing the simulated data matches pre-existent experimental data, it

can be unclear whether the accuracy of the presented results is an indicator of good model performance in terms of physical representation, or the result of coefficient tuning and/or code numerics. In fact, when the simulated operating condition is altered while leaving the setup unchanged, a deterioration of the quality of simulation is often noticed. With this in mind, three important questions arise. We will address some of them in this work while others have already been investigated by the authors in previous work or will be addressed in future publications:

1. Are the most commonly used sub models, which were derived for classical droplet evaporation and breakup processes, valid for simulating the conditions related to real diesel injection (sometimes approaching trans-critical conditions)? In this work one scenario that we will investigate is whether the continuous injection of cool spray leads to a local cooling of the gas phase around the liquid droplets and subsequent reduction of both local charge temperature and pressure and whether this cooling effect is potent enough that only the initial droplets would fall into the super/trans critical regime while the following droplets would be trans/sub critical.

2. Is there a single coefficient matrix for the various sub-models used in spray injection (namely turbulence, atomisation, evaporation, mixing) that can provide good match with experimental data at different operating conditions? This question highlights whether the mathematical fundamentals of the sub models are sophisticated enough to account for physical changes in the injection process.

3. If such a coefficient matrix does not exist, are there any trends in the change of the coefficient values linked to physical processes and boundary conditions that can guide the a priori selection of the coefficient values? This question relates to the concept of intelligent tuning strategies of physically reasonable parameters to trigger similar trends between simulations and experiments if the sub models cannot adequately replicate the real process. Should such a tuning approach be necessary, we seek to identify pre-defined values of key tuning parameters depending on the boundary conditions and some "key benchmark points". This opens the possibility of intelligent 
or even automated tuning. If such a pre-definition of tuning parameters is derivable, then lengthy tuning iterations will no longer be necessary.

Initial work towards answering the second question has been performed by the authors in (53) and (54).

The conclusions of Nsikane et al in (53) suggested that a single setup to match a range of operating conditions could not be found. While this does not prove that such a setup does not exist, the employed so called "Design of Experiment (DoE)" approach to statistically analyse hundreds of simulations unchanged. A closer inspection at microscopic spray characteristics (such as droplet statistics) would highlight that if the setup is kept unchanged, even for a narrow range, some physical changes could not be captured. This was shown to have little to no impact on the overall spray behaviour but still shows unanswered and are the main subject of the current paper. methodology is suggested where automated parameter optimisation and subsequent setup refinement deliver a setup for each condition which produces good results for multiple comparison metrics like

104 liquid and vapour penetration lengths, radial and axial mass fraction and temperature distributions. The 105 subsequent analysis then investigates the used simulation constants and analysed in which way they had 
106 to change to match the experiment and, most importantly, whether their change accurately reflect the

107 changes in the underlying physical processes triggered by the change of operating conditions.

\section{Experimental Data used for Comparison}

\section{$109 \quad 2.1 \quad$ Selection of Experimental Data}

110 For this work, a set of experiments commonly known as the ECN Spray A has been selected (see Table

111 1). For ECN "Spray A", a diesel surrogate, n-dodecane, is injected vertically through a single-hole 112 injector into a quiescent combustion chamber. Much effort has been put in to characterise the 113 specifications of the injector by the authors in (1-3) and has been summarized in Table 2.

Table 1: Selection of ECN Spray A parametric variations (56)

\begin{tabular}{|c|c|c|c|c|c|c|}
\hline $\begin{array}{c}\text { Key } \\
\text { point }\end{array}$ & $\begin{array}{c}\text { Charge } \\
\text { Temp } \\
\text { (K) }\end{array}$ & $\begin{array}{c}\text { Charge Density } \\
\left(\mathrm{kg} / \mathrm{m}^{3}\right)\end{array}$ & $\begin{array}{l}\text { Charge } \\
\text { Pressure } \\
(\mathrm{MPa})\end{array}$ & $\begin{array}{c}\text { Inj. } \\
\text { Pressure } \\
\text { (MPa) }\end{array}$ & $\begin{array}{c}\text { Injector } \\
\text { (\#) }\end{array}$ & $\begin{array}{c}\text { Mixing } \\
\text { regime } \\
\text { classification } \\
T_{r} \sqrt{P_{r}} \\
\end{array}$ \\
\hline 1 & \multirow{3}{*}{900} & \multirow{3}{*}{22.8} & 6.05 & 150 & \multirow{5}{*}{$\begin{array}{l}210677 \\
\text { (Sandia } \\
\text { NL) }\end{array}$} & \multirow{3}{*}{2.49} \\
\hline 2 & & & \multirow{2}{*}{6.07} & 100 & & \\
\hline 3 & & & & 50 & & \\
\hline 4 & 1100 & 15.2 & 4.96 & \multirow{2}{*}{150} & & 2.76 \\
\hline 5 & 1400 & 7.6 & 3.19 & & & 2.82 \\
\hline
\end{tabular}

115

Table 2: ECN Spray A injector specifications (57)

Fuel injection equipment
Bosch solenoid-activated, generation 2.2
$90 \mu \mathrm{m}$
1.5
Hydro-eroded
$0.2 \mathrm{~mm}^{3}$
$\mathrm{C}_{\mathrm{d}}=0.86$, using $10 \mathrm{MPa}$ pressure drop

Nozzle K factor

Nozzle shaping

Mini-sac volume

Discharge coefficient 
Fuel specifications

\begin{tabular}{l|r}
\hline Fuel & n-dodecane \\
Fuel temperature at nozzle & $363 \mathrm{~K}\left(90^{\circ} \mathrm{C}\right)$
\end{tabular}

117

\subsection{Droplet mixing regime of ECN Spray A}

A shift of a liquid droplet from classical atomisation and vaporisation (subcritical) into the supercritical regime is characterised by the diminishing of droplet surface tension. This phenomenon occurs at a combination of high temperature and high pressures above the critical point of the fluid. In common diesel injection conditions, the liquid fuel all the way through the injector is subcritical. However, the ambient gas the liquid is injected into is typically in the supercritical regime of the fuel. As the fuel exits the nozzle, heat transfer processes will elevate the temperature of the fuel while simultaneously reducing the local temperature and pressure of the surrounding gas. There is still ambiguity among the scientific community as to whether a cool spray injected into a supercritical environment ultimately represents a supercritical spray or not. It is generally very difficult to observe the highly dynamic diffusive mixing (supercritical evaporation) process experimentally primarily due to technical limitation of the equipment (58-60). The absence of conclusive results has led to researchers try to identify supercritical characteristics of flows based on secondary evidence like macroscopic changes in the physical appearance of the plume (61-63). Crua et al in (64) eventually succeeded in capturing the droplet breakup and evaporation process and developed a conceptual model of the droplet mixing regimes shown in Figure 1. This work was based on a range of single component fuels injected through a single-hole injector into a quiescent vessel at various operating conditions. The authors show clear 
135 evidence that despite the ambient conditions being supercritical, surface tension and primary 136 atomization for n-dodecane can be observed, hence categorising the spray well within the 'classical 137 evaporation' regime. They further show that even in cases where ambient conditions are so extreme 138 that the fuel ultimately undergoes diffusive mixing, there is still a finite transition time which depends 139 on local gas temperatures and pressures as well as on the fuel's physical properties. This finding is of 140 fundamental importance for this work because it justifies the use of the classical sub models which 141 usually account for surface tension effects and would potentially not be valid for flows entering the 142 "transitional mixing" regime or beyond. Recent attempts of simulations of supercritical flows can be 143 found for example by Chung et al in (65).

a) Classical evaporation $T_{r} \sqrt{P_{r}} \leq 3.3$

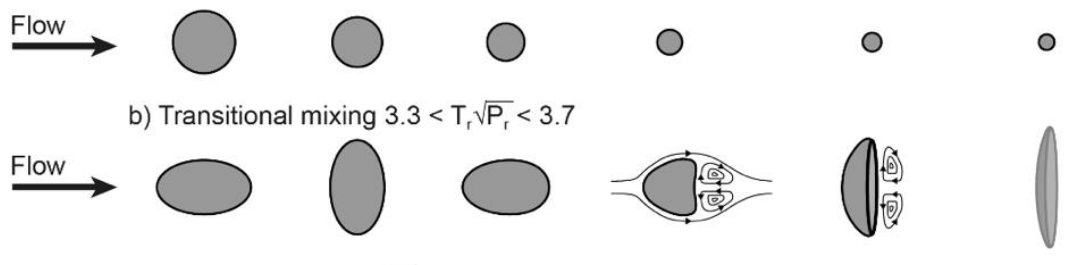

c) Diffusive mixing $T_{r} \sqrt{P_{r}} \geq 3.7$
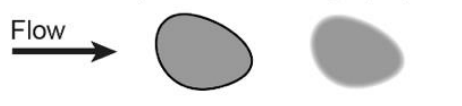

Figure 1: Conceptual model of droplet mixing regimes (64)

146 Despite the results from Crua et al in (64), some technical limitations to their approach are important to

147 highlight. A visualisation of the individual droplets was only possible at the end of injection for 148 relatively slow droplets and in an optically thin region of the spray. Physical processes within the core 149 or the optically dense region of the spray remained unresolved. This is where CFD has the potential to 150 offer some insight by assessing the temperature and pressure conditions in the optically dense region, 151 so that a categorisation of the droplet mixing regimes can be attempted.

152 The ECN Spray A variations investigated here were also central conditions in the work by Crua et al in 153 (64) where they developed a droplet mixing regime classification system (see Figure 2). The left image 154 shows the nominal chamber pressure over charge temperature of a range of operating conditions. 155 Following this, the axes were normalized by dividing the far-field values ( $\mathrm{Tg}, \mathrm{Pg}$ ) by the fuel specific 
critical temperature and pressure values Tc and Pc. A regression model with the best fit at $T_{r} \sqrt{P_{r}}$ allowed the automated classification seen on the right image. We have superimposed the key points selected for this work (see Table 1) onto Figure 2, which clearly shows that they would all clearly fall into the "classical evaporation" regime despite the ambient conditions being supercritical.

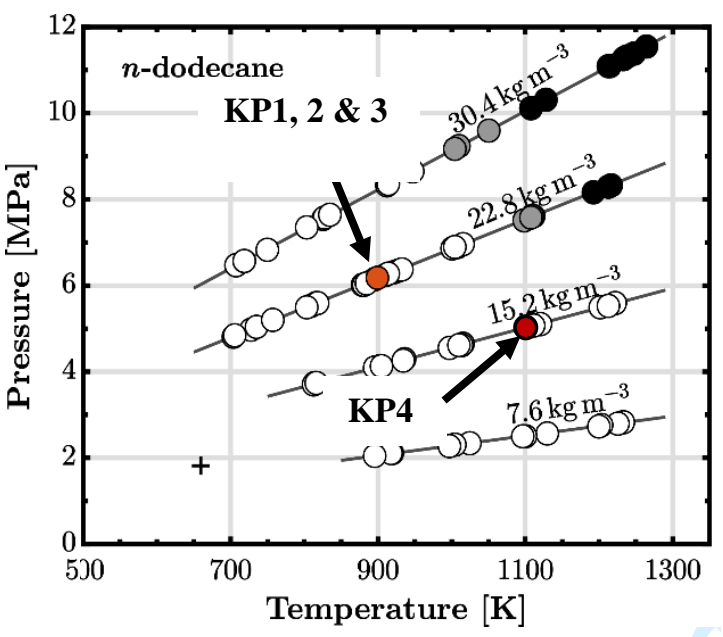

160

161

162

163

164

165

166

167

168

169

170

\section{Numerical Setup}

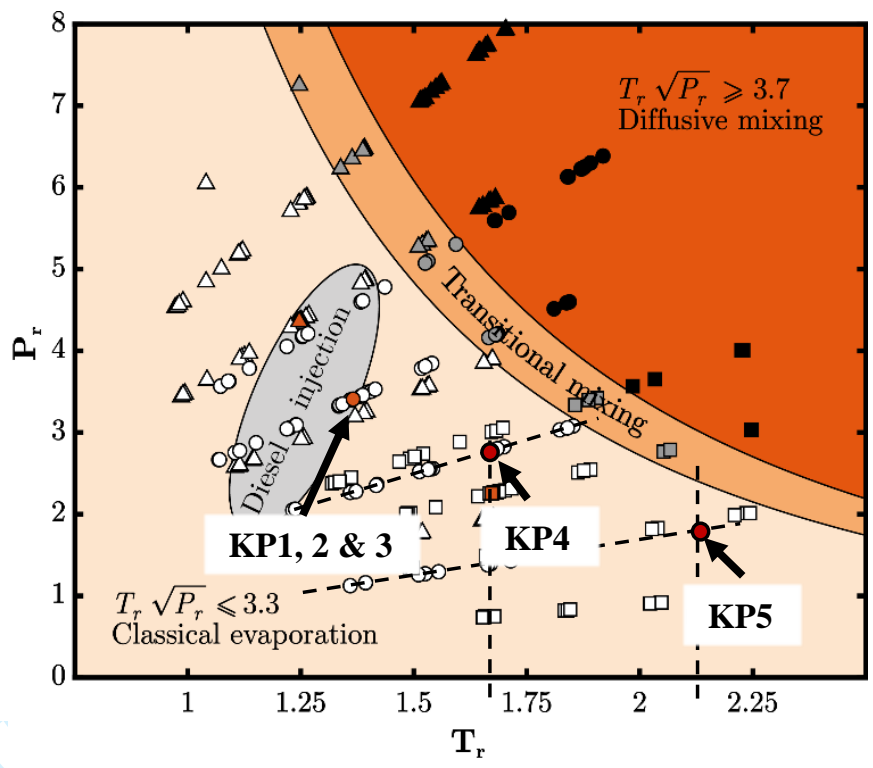

$\Delta n$-hexadecane $\circ n$-dodecane $\square n$-heptane

Figure 2: Gas pressure-temperature diagrams for n-dodecane (left). The left diagram is then projected onto a classification of mixing regime diagram on the right. Both Pr and Tr are calculated by dividing the imposed far-field $(\mathrm{Pg}, \mathrm{Tg})$ values by the critical values of the fuel (For $\mathrm{n}$-dodecane $\mathrm{Pc}=18.2 \mathrm{bar}, \mathrm{Tc}=658 \mathrm{~K})$. ( $\operatorname{Reproduced}$ from $(64)$, red symbols indicate the operating conditions examined in our work.)

The study is conducted with Ricardo Software's commercially available CFD package VECTIS. It is a RANS based code with a long history of extensive industrial use for ICE's and is well validated (66). The used sub-models are largely industry standard and can be also found in most other commercially available CFD solvers. This allows for the approach presented here to be applied on other CFD packages. Further, the same DoE optimization approach can also be taken in an LES framework.

The usual mesh and time-step independence studies were conducted to ensure model convergence. Independence is found for a mesh size of $0.45 \mathrm{x} 0.45 \mathrm{~mm}$ ( 1 335096 cells $)$ and a time step of 5e-7s (53). 
173 These settings can be carried over throughout the investigation. The selected sub models are listed in $174 \quad$ Table 3.

Table 3: List of selected sub models

\section{Design of Experiment}

Both in research and in industrial applications, experiments play a key role in

Turbulence Model

Spray Injection Method

Droplet Tracking method

Droplet Breakup Model

Droplet Drag Model

Droplet evaporation

Phase interaction
Selected sub models

\section{Standard k- $\varepsilon(67)$ \\ Blob (Single size) \\ Eularian-Lagrangian}

KH-RT with Levich switching criterion $(68,69)$

Putnam (70)

Spalding correlation $(71,72)$

Droplet-droplet \& droplet-turbulence (two-way coupling)

- Identifying the influence of input parameters on output parameters within a system

- Highlighting the sensitivity of the system towards changing conditions

- Finding a combination of input parameters which produce a desired output

183 investigations, a statistical approach to analyse the data can significantly reduce the burden. DoE is such

184 an approach. In engine $R \& D, D o E$ is a common tool to visualise complex interactions and sensitivities 185 in the system. It is important to note that DoE only highlights connections between independent (input) 186 and dependent (response) variables but cannot give explanations to the fundamental processes. For a 187 reliable connection between cause and effect to be made, a statistical relevant number of experiments 188 must be conducted. The mathematical fundamentals of the simulation's sub models (see Appendix) 189 show that the response of the CFD simulation relies on several user defined input variables. The DoE 190 software used for this study is a Ricardo in-house tool called $\eta$ Cal. In the following sections we will 
191 briefly describe the main steps followed in this work to build our DoE. The mathematical background 192 of the $\eta$ Cal tool is given in (73) and has been extended by Ricardo to deal with noisy data for engine 193 test data. It should be underlined that part of the novelty of this work is that our effort is not only limited 194 to identify links between independent (input) and dependent (response) variables as traditional DoE's 195 do but also to unveil a physical explanation of these trends.

\section{$196 \quad 4.1 \quad$ Simulation Design Matrix}

Input parameters

198 A screening and selection process of the available sub models and their user definable parameters 199 yielded a selection of 10 influential parameters. For the DoE approach to be considered statistically 200 relevant, 10 simulations per input parameter are required, hence 100 simulations for every DoE key 201 point. Each of these runs has an input parameter combination which is defined by the software to ensure 202 they are evenly distributed across the design space (stochastic process). The ranges in which the 203 parameters vary were defined following the recommendations by the original authors and the VECTIS 204 documentation. The DoE parameters, their range and phenomenological significance is collected in 205 Table 4. Previous work (see (53)) showed how in these cases, an adjustment of $\mathrm{C}_{2}$ was selected to 206 achieve good results. In our more recent studies, both $C_{1}$ and $C_{2}$ are considered as DoE variables. The 207 initial droplet diameter and the half cone angle are not part of any model, are however typically 208 unknown and treated as simulation parameters. Although the coefficients are grouped, it is important to 209 realise that they are intertwined i.e. an initial condition like the droplet size will influence the mixing 210 and combustion.

Table 4: Selected simulation constants and their physical implication

\begin{tabular}{|c|c|c|c|}
\hline Parameter & Range & Phenomenon & Group \\
\hline Coefficient of Dissipation $\mathrm{C}_{2}(-)$ & $1.65-1.9$ & Destruction of Turbulence & $\begin{array}{c}\text { Turbulence } \\
\text { Coefficients }\end{array}$ \\
\hline Drag scaling factor $\mathrm{A}_{\text {drag }}(-)$ & $0.2-1.5$ & Liquid/Gas Momentum Transfer & \\
\cline { 1 - 3 } $\mathrm{KH} \mathrm{B}_{1}-$ Constant (-) & $1-40$ & Primary Atomization & \\
\cline { 1 - 3 } & & & \\
\cline { 1 - 3 } & & &
\end{tabular}




\begin{tabular}{|c|c|c|c|}
\hline $\mathrm{KH} \mathrm{B}_{0}-$ Constant (-) & $0.3-0.8$ & Primary Atomization & \multirow{4}{*}{$\begin{array}{c}\text { Droplet } \\
\text { Breakup } \\
\text { Coefficients }\end{array}$} \\
\hline RT $\mathrm{C}_{\mathrm{RT}}-$ Constant (-) & $0.3-2$ & Secondary Atomization & \\
\hline $\mathrm{RT}-\mathrm{C}_{3}-$ Constant (-) & $0.3-5.3$ & Secondary Atomization & \\
\hline Levich $\mathrm{A}_{b u}-$ Constant (-) & $5-12$ & Primary/Secondary Atomization & \\
\hline Initial droplet diameter $\mathrm{D}_{0}(\mu \mathrm{m})$ & $60-90$ & Droplet Introduction & \multirow{2}{*}{$\begin{array}{c}\text { Initial } \\
\text { conditions }\end{array}$} \\
\hline Initial Half Cone Angle $\alpha_{\text {cone }}(\operatorname{deg})$ & $2.5-7.5$ & Initial Dispersion & \\
\hline
\end{tabular}

212

\section{Response parameters}

214 To assess the quality of a simulation, the root-mean-square-error (RMSE) between the response 215 parameter (like vapour penetration etc.) and the experimental data from the ECN is calculated. This 216 allows a quantification of the similarity between the experimental and calculated curve progressions 217 and provides the input for the stochastic process model (SPM). To avoid skewed results, extreme 218 transients in the curves are avoided (i.e. ROI ramp up/down). The approach is described in Table 5. The 219 response parameters in this work are the liquid spray and vapor jet penetrations. The mass fraction 220 distributions were initially also considered as target metrics, but due to the optimizer only allowing a 221 limited number of target parameters, it was decided to use these data sets as secondary validation 222 metrics. Once reliable local droplet size statistics of the dense spray become available, they could be added as target metric to calibrate the response to microscopic spray characteristics.

Table 5: Mathematical background for RMSE approach

\begin{tabular}{|c|c|c|c|c|c|}
\hline Case & $\begin{array}{l}\text { Time } \\
\text { step }\end{array}$ & $\begin{array}{l}\text { Metric } \\
\text { Value }\end{array}$ & $\begin{array}{c}\text { No. of time } \\
\text { steps }\end{array}$ & \multirow{3}{*}{$R M S E=$} & \\
\hline Experiment & \multirow[t]{2}{*}{$t$} & $x_{1, t}$ & \multirow[t]{2}{*}{$n_{t}$} & & 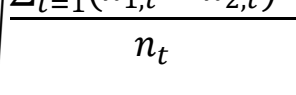 \\
\hline Simulation & & $x_{2, t}$ & & & \\
\hline
\end{tabular}


226

227

228

231

232

233

234

235

236

237

238

239

240

241

242

243

244

\subsection{DoE Optimisation}

There are too many parameter combinations which could lead to a matching solution to be analysed manually. To narrow down viable solutions, a built-in optimizer is equipped with user defined target conditions is used. The optimizer creates a pareto diagram and compiles a list of combinations of input parameters which fulfil the target condition. Since there is not a best solution for these criteria, the optimizer will provide multiple solutions ( 15 options). To further narrow down the number of solutions non-physical combinations are excluded. The non-physical combinations are considered to be those where multiple values of the DoE constants are gathered at the periphery of their range. A matrix with a single value at the extreme end of a range is still considered. The remaining few solutions ( $\sim 5$ options) are scrutinized by investigating the mass fraction and gas temperature distributions, the microscopic characteristics like droplet sizes, their transient regions of injection ramp up \& down and how they behave to changing boundary conditions. A quality criterion would for example be that at discrete injection pressure increase (with unchanged chamber conditions) a simulation setup at each condition can be found that together exhibit a sweep in values which are related to an injection pressure swing.

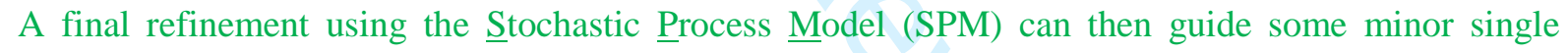
parameter adjustments to arrive at the best setup. Due to the uncertainty of the SPM it is possible that the optimiser offers a theoretically optimal solution (small RMSE's) that when simulated show shortcomings. Owing to the steep gradients of the RMSE sensitivity of some key simulation constants, the settings may need some adjustment slightly to produce good results. Since both results for both setups will be presented later, they will be referred to as "DoE Setup" and "Refined Setup".

This single parameter adjustment using the graphical representation of the SPM differs from the commonly used single parameter swing method criticised in the introduction in a way that will be described in detail in section 5.2. In short, using the graphical SPM interface, one can change the value of any simulation constant and observe the impact it would have on the liquid or vapor RMSE. It also shows the how sensitivities of all other constants change and whether any additional adjustments would become necessary to reduce the RMSE further. 
252

253

254

255

256

257

258

259

260

261

262

263

264

265

266

267

268

269

270

271

272

273

274

275

276

\subsection{Computational effort}

The average duration per simulation over a $4 \mathrm{~ms}$ injection duration on 20 cores Intel(R) Xeon(R) CPU E5-2650 v3 CPUs with $2.30 \mathrm{GHz}$ in this work is $2 \mathrm{hrs}$. Other high quality simulations with which include detailed or reduced chemistry solvers, LES approaches for turbulence modelling and finer grids have shown to have runtimes that are higher by one, or in some cases two, orders of magnitudes $(36,74)$. This brief comparison highlights the potential time benefit of using simplified models over detailed solvers, though intelligent tuning becomes of utmost importance.

\section{$5 \quad$ Results and Discussion}

\subsection{Microscopic Analysis of Baseline Spray A}

Before we demonstrate the accuracy of the CFD calculations on macroscopic metrics, we must get a better insight into the droplet behaviour. It should be pointed out that in some cases a physically "wrong" model with extreme coefficient tuning might be able to reproduce some of the experimental results. In order to establish that this is not the case here we include the following results. These results are complimentary to the observations of section 2.2 and are used to show why the simulated conditions are indeed subcritical.

The left side of Figure 3 shows contour plots of charge temperature of the baseline (KP1) from the start of injection up to the steady state phase (liquid penetration stabilising) in $0.1 \mathrm{~ms}$ increments. It also shows a qualitative representation of the droplet mean diameter and a quantitative contour plot of the droplet temperatures. Just after the start of injection (first row, 0.05 ASOI), the liquid jet of KP 1 starts reducing the charge temperature around $5 \mathrm{~mm}$ downstream the nozzle. The droplets in this area begin to rapidly heat up by absorbing thermal energy from the surrounding air leading to their evaporation. Within this low temperature zone, some following droplets begin to coalesce instead of evaporating. These large droplets then penetrate through the surrounding air while evaporating downstream relatively slowly. Despite these cases being under evaporating conditions, some parallels can be drawn to the process described by Magnotti et al in (75) where under non-evaporating conditions shortly after 
injection some degree of droplet coalescence was observed. We assume that once the cooled initial 278 stagnant air is removed by liquid jet induced turbulence, the low temperature zone stabilizes at higher 279 temperatures preventing any further coalescing. As of $0.3 \mathrm{~ms}$ ASOI, the steady state is established, and 280 the droplets complete their breakup and evaporation process around $10 \mathrm{~mm}$ downstream the nozzle. 281 These images indicate that due to high droplet velocities, the droplets only begin to show considerable 282 heating around $4 \mathrm{~mm}$ downstream presumably due to thermal inertia. This is the first important point supporting the conclusions by Crua et al in (64) that essentially only droplets further downstream might 284 reach to critical temperatures. A further investigation into the development of the temperature 285 conditions of the gas phase around the spray injection region is shown on the right side of Figure 3 . The 286 radial temperature distributions of incremental slices at given time steps are plotted as a wireframe. The 287 temperature is normalised with n-dodecane's critical temperature to match the characterization 288 previously shown in Figure 2. The significance of this graph is that we can observe a local cooling along 289 the centre axis leading to a drop of Tr. The consequence is effectively a shift to the left of the location 290 of the key point in Figure 2 for the transient phase of the injection process. These findings also apply 291 for all other invested key points. 

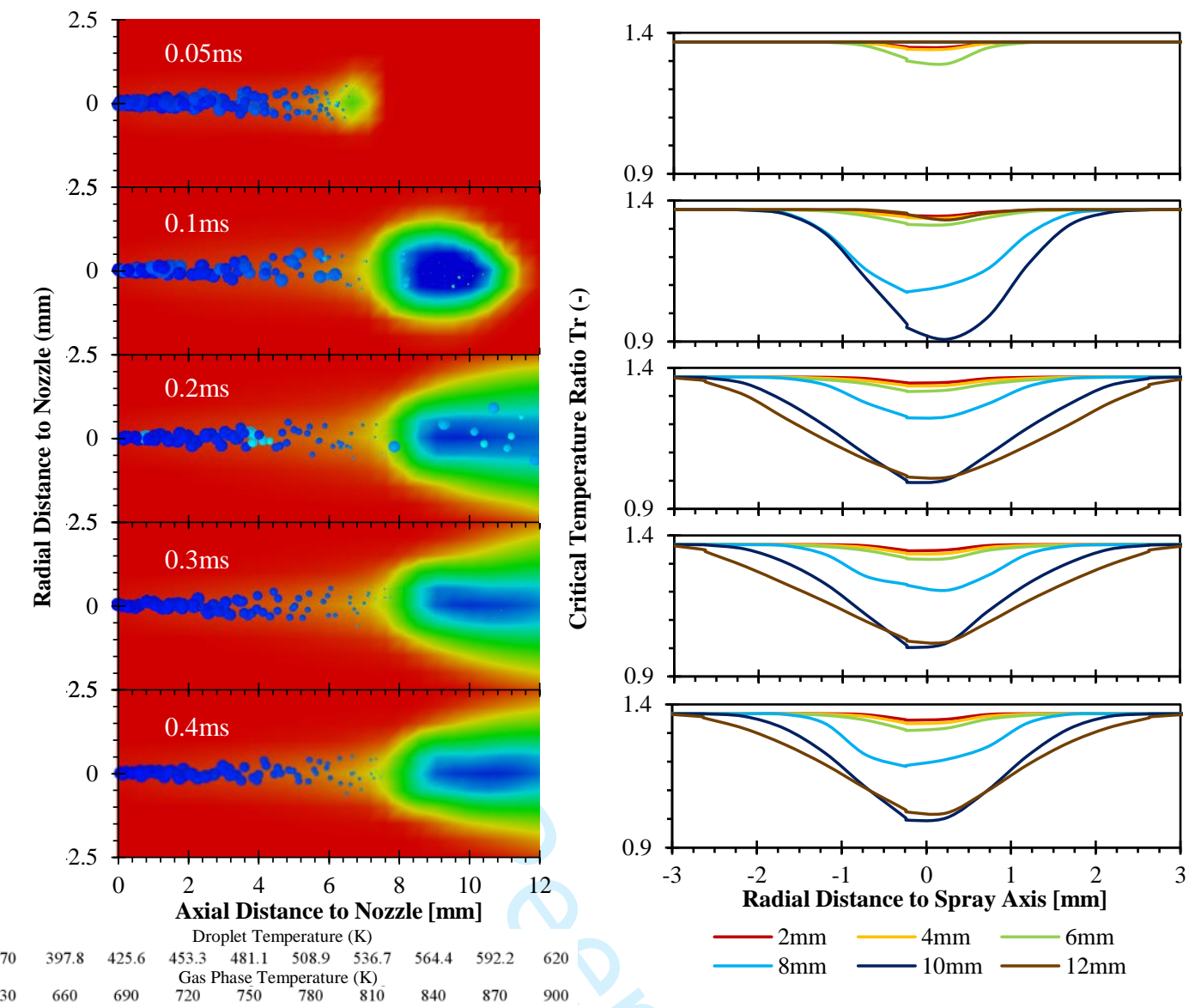

Figure 3: Charge temperature, droplet sizes (scaled qualitatively) and droplet temperatures (colour scale) at various time steps (left) and the corresponding radial critical temperature ratio distributions at six axial locations for the baseline ECN Spray A (KP1) (right)

297 With the spray being placed well within the conventional evaporation regime it is justified to continue our approach with conventional spray models. The process outlined in section 4 is followed for all spray cases (KPs 1-5). At each key point, 100 simulations are run. Following the optimisation and manual refinement, a setup for each condition was found to match the experimental liquid and vapour penetration. The reasons for the refinement of the optimised solution are due to the uncertainty in the

Figure 4 shows the SPM's of all five key points at their refined setup. The significance of the constants on the x-axis are explained in Table 4. Each field in the rows represent the RMSE between the experiments and simulations (see Eq 1) as a function of the parameter in the column. The $\mathrm{x}$-axes with 
306 the constant value in the column have been removed for confidentiality reason, which however does

307 not obstruct the qualitative nature of the graph. The gradient represents the sensitivity of the RMSE

308 towards a change of that parameter. The dotted lines represent $2 \sigma$ confidence of the prediction.

309 In Figure 4, the coefficient of dissipation $C_{2}$ shows to have a significant impact on the vapour 310 penetration and only little on the liquid penetration. This makes $\mathrm{C}_{2}$ the single most influential parameter

311 to adjust the vapour penetration. This constant also shows a clear minimum which indicates that there

312 is only a small range in which it may vary. The axial location of this minimum, which represents the 313 constant's value, does not vary with operating condition.

314 The drag scaling coefficient $A_{\text {drag }}$ which influences the liquid/gas momentum transfer (Eq 4) is crucial 315 for liquid and to some extent vapor penetration. For key points $1-4$, we assume there is a minimum 316 beyond the investigated range, leaving merit to extend the ranges in future work. However, not 317 including the minima's does not hinder the results because the trade-off required to keep vapor RMSE 318 low requires selecting a value within the range. The steep inclinations of the RMSE curves and different 319 value for each condition highlight the condition sensitivity of this parameter. Generally, a reduction of 320 RMSE sensitivity with decreasing density can be observed (compare absolute maximum liquid RMSE 321 between KP 1,4 \& 5). Additionally, key point $5(1400 \mathrm{~K}, 7.6 \mathrm{~kg} / \mathrm{m} 3,150 \mathrm{MPa})$ shows a clear increase 322 for required absolute parameter value.

323 The $\mathrm{KH}-\mathrm{B}_{1}$ constant, which influences the primary breakup time scale (Eq 7, appendix) is also 324 paramount for liquid length calculations. However, unlike the characteristics of the drag scaling 325 coefficient, $\mathrm{KH}-\mathrm{B}_{1}$ shows its minimum at approximately the same axial location and similar absolute 326 RMSE sensitive at all key points. This means that although $\mathrm{KH}-\mathrm{B}_{1}$ is an influential parameter, the 327 variations of the absolute value between conditions are small and therefore justify the parameter to be 328 held constant across key points. In most cases (except KP 2), the minimum found for liquid RMSE 329 appears to be an acceptable value for the vapor RMSE. The reasons for KP 2's deviation from this 330 pattern are unclear at this point 
331 The impact of the remaining coefficients remains small relative to the above. Changes of their value 332 have little influence on the absolute RMSE of liquid and vapor penetration. This is not to say that they 333 are not important as they do affect the microscopic characteristic of the spray plume. For example, work 334 done in context of initial trialling of the tabulation on reactive cases has shown initial droplet sizes and 335 the $\mathrm{RT}_{3}$ - constant to be influential for secondary droplet sizes which influence combustion 336 characteristics for combusting cases. Given some quantitative droplet size measurements at any location 337 of the spray plume, an additional target metric for the DoE could increase accuracy of the response of 338 the simulation constants that are more influential for microscopic spray characteristics. While not 339 influential here, the turbulent Schmidt number has shown to become more influential under realistic 340 engine conditions with swirl motion and fuel injection through a multi hole injector. 


\section{1}

2

3 4 6

341

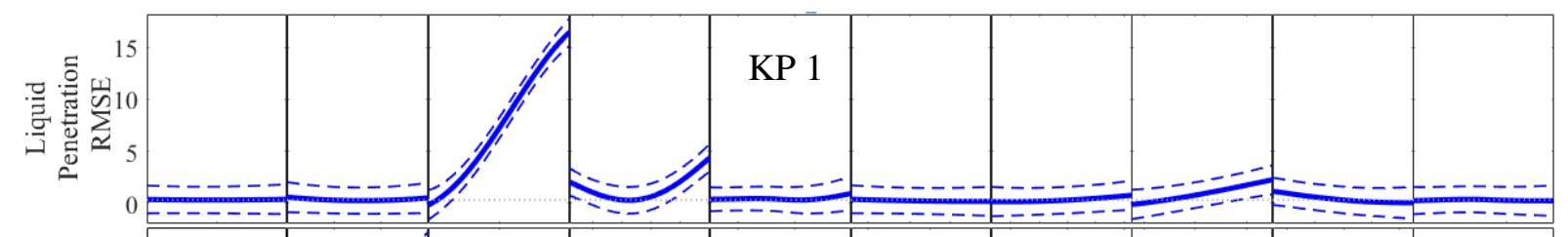

342

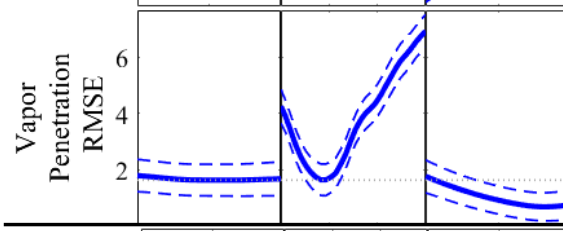

\section{3}

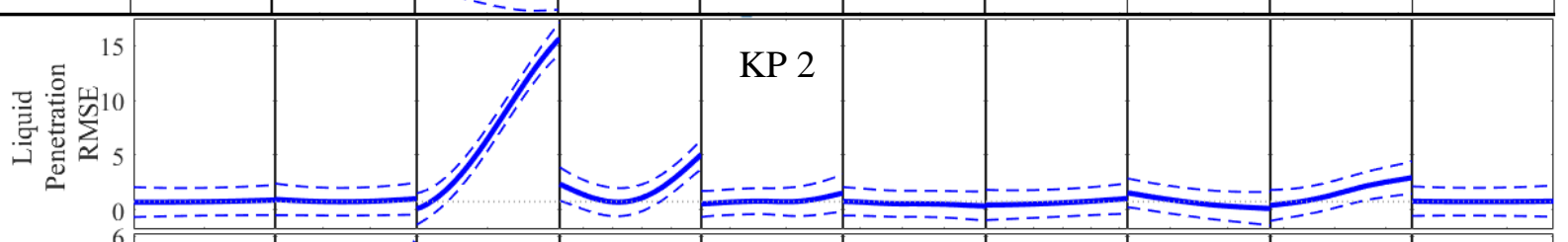

344
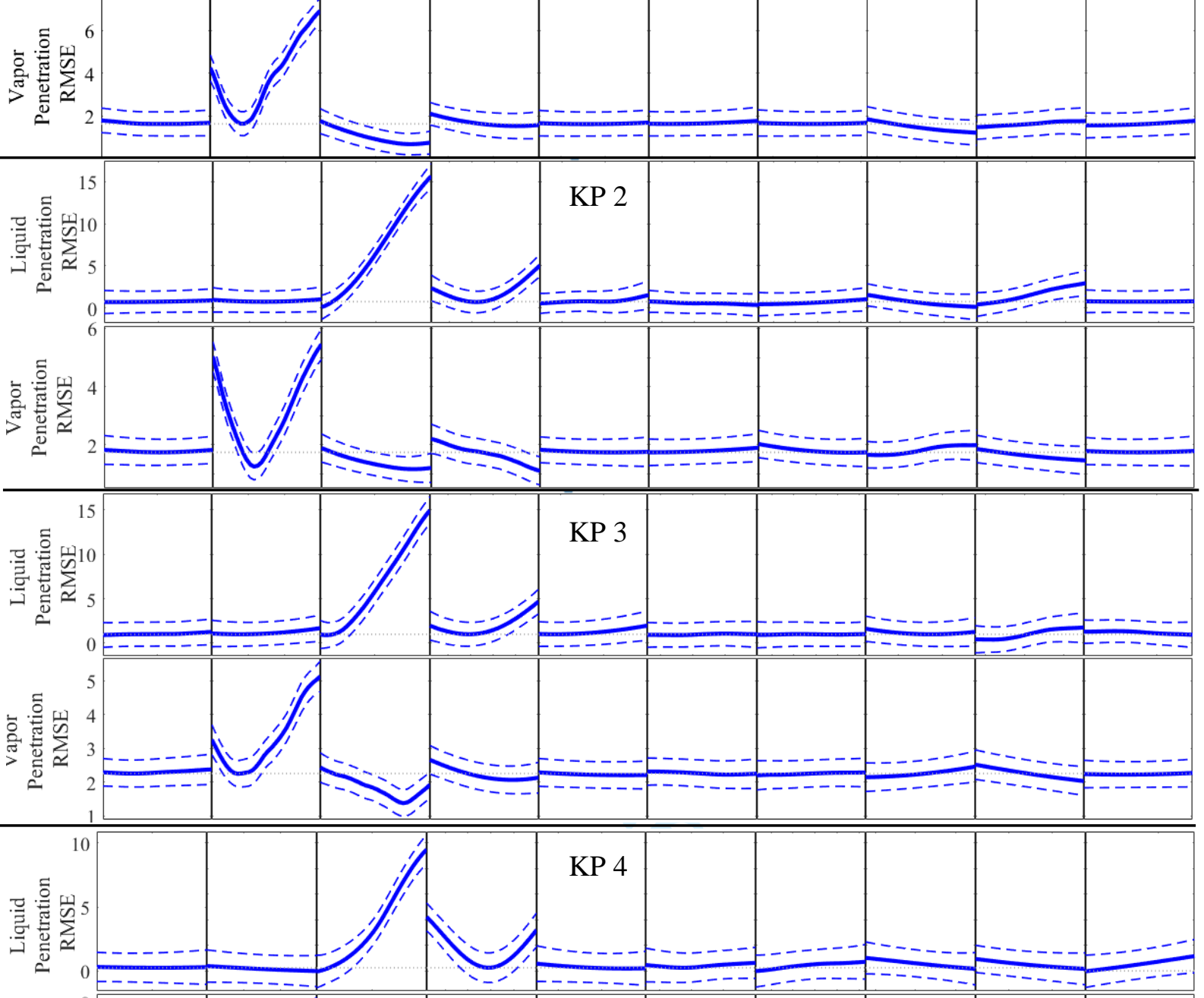

Figure 4: Graphical representation of the stochastic process model (SPM) that highlights sensitivities of the result on a

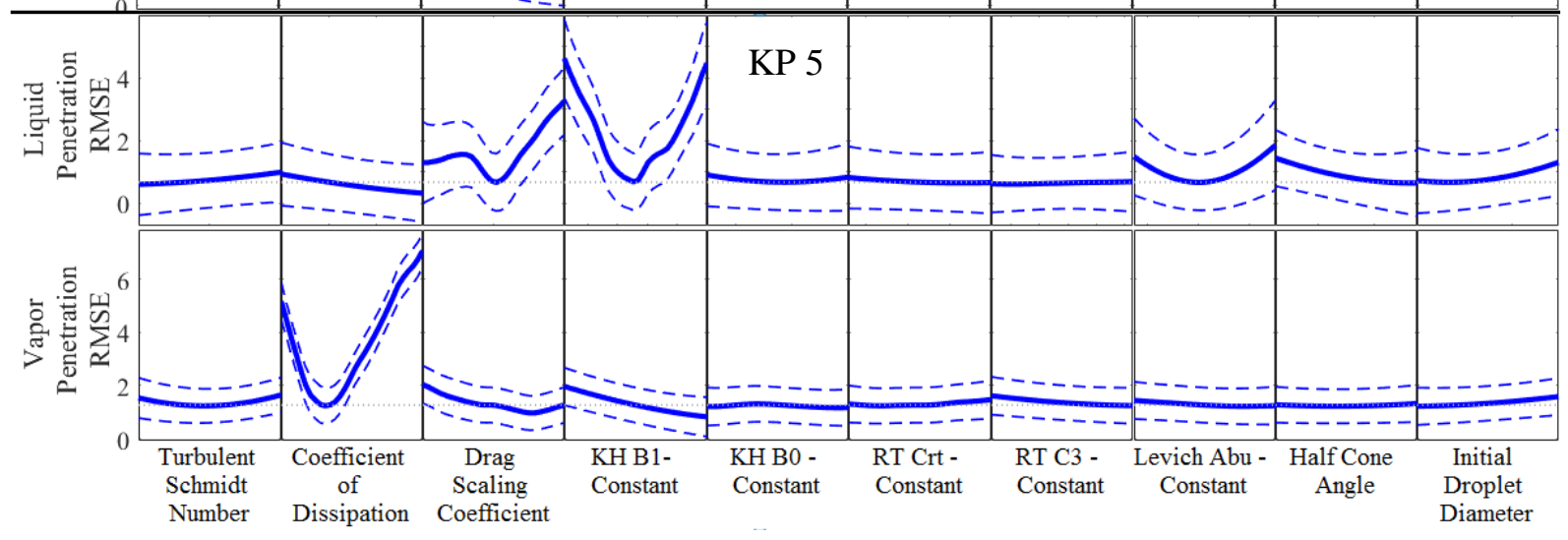
change of parameter value for all key points (from KP 1 at the top to KP 5 at the bottom) 
5.3 Spray evaporation and mixture formation under inert conditions

350

352

\subsubsection{Results of Design-of-Experiment approach on mixture formation under constant injection pressure and changing chamber conditions}

In this section we turn our attention to the key points (KP $4 \& 5$ ) which differ both in charge density and temperature from the baseline (KP 1). The experimental data shown in Figures 5 and 6 (hollow symbols) are not directly comparable as both density and temperature change simultaneously. Nevertheless, some interesting observations can be made from the progression of liquid and vapour penetration. In the case of an isolated charge temperature increase, it can be assumed the liquid penetration would decrease with increasing charge temperature due to increased droplet evaporation. Vice-versa, an isolated decrease of chamber density would increase liquid penetration (76). When these two effects happen simultaneously, the effects partially counteract each other until one of the effects becomes dominant.

The authors see strong indication of this phenomena occurring in the cases shown in Figure 5. As the charge temperature increases and charge density inversely decreases from KP 1 to 4, the liquid penetration slightly decreases. This decrease is potentially due to the change in the evaporation rate. When this progression continues to KP 5, the liquid penetration increases significantly (see Figure 6). The authors suggest that while between KP1 and 4 the temperature influence is slightly stronger, density effects become dominant between KP 4 and 5. The vapour penetration shows a clear sensitivity to reducing chamber density, presumably due to reduced aerodynamic resistance and subsequent dissipation. An isolated temperature increase under constant density is not thought to have much effect on the vapour motion. For KP 1, the ECN baseline at $900 \mathrm{~K}, 22,8 \mathrm{~kg} / \mathrm{m} 3$ and $150 \mathrm{MPa}$, no experimental error in the liquid penetration is stated, however is not expected to be significantly different to other four cases.

Figure 5 shows a comparison between the DoE optimised setup, the manually refined setup and the ECN test data of liquid penetration length over charge density. Figure 5 shows that the settings from 
374 the "Refined setup" produce average liquid lengths within the supplied error bands of the experimental 375 data.

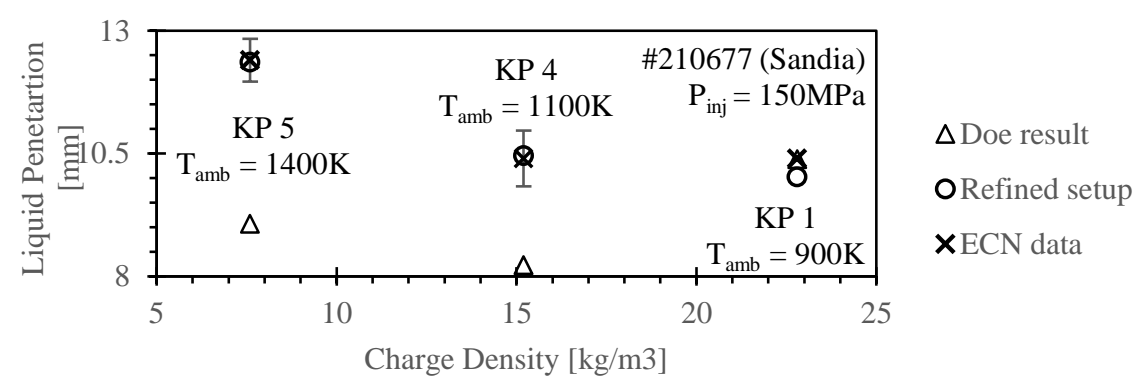

Figure 5: Simulation vs experimental data of liquid penetration of three different charge temperature and density conditions at constant injection pressure

379 The overall smaller RMSE range (see Figure 4) for vapor penetration means the setup is more robust to

380 changes of even the most sensitive constant. The effect on vapor penetration is not pronounced therefore 381 Figure 6 only shows the results for the "Refined setup". The temporal spray tip evolution is well 382 captured at all three conditions, however show some merit to improvement in the time between 0.5 and $3831.5 \mathrm{~ms}$.

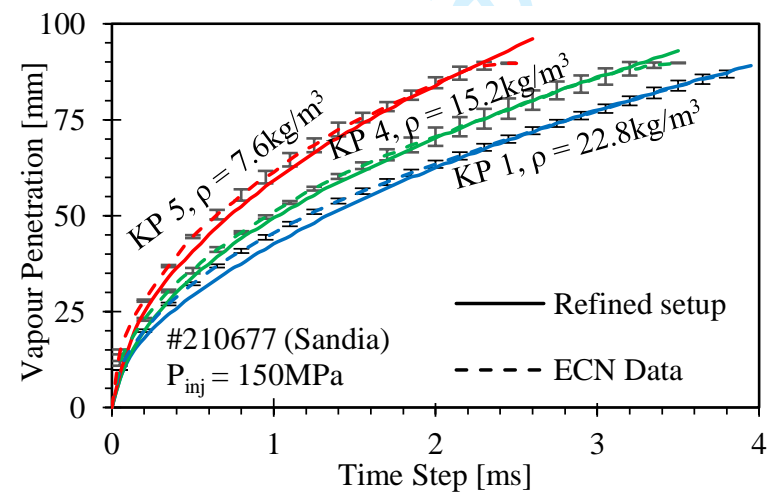

Figure 6: Simulation vs experimental data of vapour penetration of three different charge temperature and density conditions at constant injection pressure

387 To increase confidence in the simulated mixture preparation, the radial mass fraction and gas phase 388 temperature distributions at three plume cross sections and axial mass fraction along the centreline of 389 the plume are compared to available experimental data captured at a steady state time interval. The 390 results are shown in Figure 7. In all metrics, the simulations perform well and, where available, lie 
391 within the stated experimental error. No mass fraction and temperature measurements were taken for 392 the 1400K key point (KP 5) because of increasing measurement uncertainties due to the experimentally 393 challenging in-cylinder conditions. Where data is available, all metrics of the simulated data lie within 394 or very close to the experimental error.
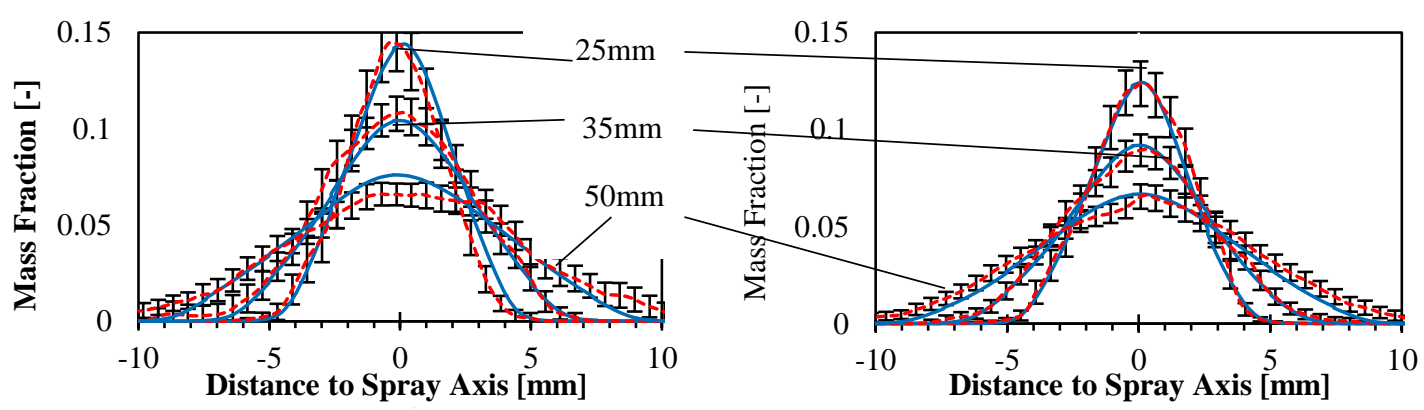

395
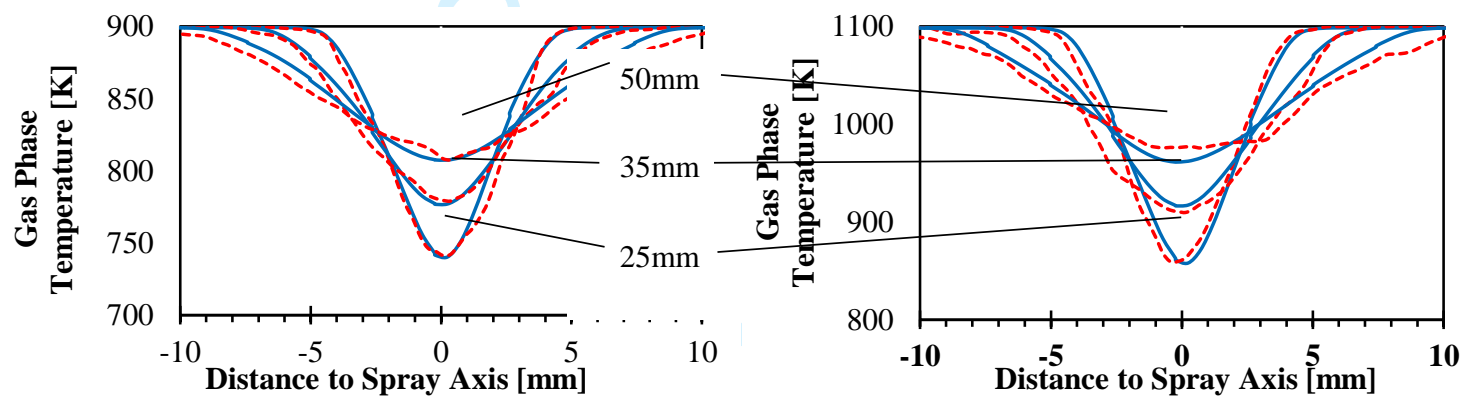

396
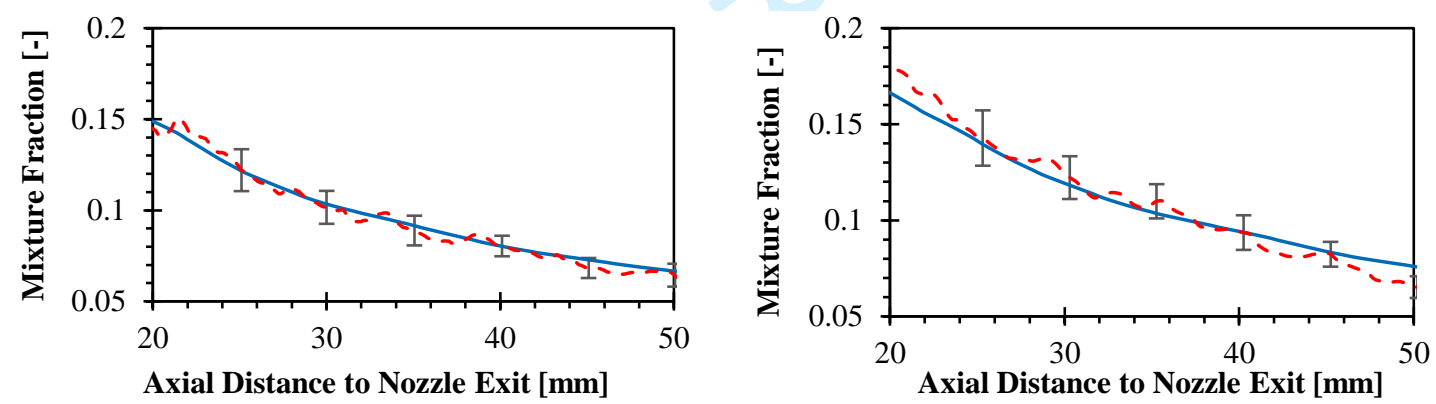

397

Axial Distance to Nozzle Exit [mm]

Axial Distance to Nozzle Exit [mm]

398 Figure 7: Comparison of radial mass fraction and gas phase temperature distribution at $25, \mathbf{3 5}$ and $\mathbf{5 0 m m}$ at $4 \mathrm{~ms}\left(1^{\text {st }}\right.$ 399 400 and $2^{\text {nd }}$ row) and centre axis mass fraction distribution at $3.2 \mathrm{~ms}\left(3^{\text {rd }}\right.$ row) between ECN test data (77) (red, dotted) and simulation (blue, solid) (KP 1, left column and KP4, right column)

401 The analysis of the simulation setups required to match test data for these three conditions is 402 summarised qualitatively in Figure 8. Upward or downward facing arrows signify a drop or an increase 403 of the parameter value in comparison to the selected reference condition (KP 1). The symbol shown in 404 bold means that the change is significant. A point indicates that the parameters remain unchanged. In 405 Figure 4 the turbulence coefficient $\mathrm{C}_{2}$ and primary breakup time-scale $\mathrm{B}_{1}$ showed that they were 
generally highly sensitive, but once the correct value is found, they may remain constant for all cases.

The drag scaling factor $\mathrm{A}_{\text {drag }}$ was found to increase with decreasing density, resulting in less of the droplet momentum being passed onto the vapour phase. This increase is physically justifiable with a decrease in aerodynamic effects that occur at lower gas densities. Given that $\mathrm{A}_{\text {drag }}$ indicates the deviation of the droplets from sphericity, we can conclude that the need to increase $\mathrm{A}_{\text {drag }}$ with decreasing density would indicate that generated droplets are more spherically shaped rather than ellipsoid. In fact, for KP 5, where density is lowest, $A_{\text {drag }}$ even approached unity while being far smaller for the other two conditions.

\begin{tabular}{|c|c|c|c|c|c|c|}
\hline $\mathrm{KP}$ & $A_{\text {drag }}$ & $\mathrm{B}_{1}$ & $\mathrm{C}_{2}$ & $\begin{array}{c}\text { Droplet } \\
\text { Diameter }\end{array}$ & \multirow{4}{*}{$\begin{array}{c}\uparrow \\
\downarrow \\
\bullet \\
\text { Bold }\end{array}$} & \multirow{4}{*}{$\begin{array}{l}\text { value increase } \\
\text { value decrease } \\
\text { near stagnant } \\
\text { significant change }\end{array}$} \\
\hline 1 & \multicolumn{4}{|c|}{ Reference key point } & & \\
\hline 4 & $\Lambda$ & $\bullet$ & $\bullet$ & 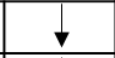 & & \\
\hline 5 & & $\bullet$ & $\bullet$ & $\downarrow$ & & \\
\hline
\end{tabular}

Figure 8: Identified relative adjustments for the main tuning coefficients between the key points 1, 4 and 5 (increasing charge temperatures/decreasing charge densities)

\subsubsection{Results of Design-of-Experiment approach under changing injection pressure and constant} chamber conditions

The experimental data shows that while the liquid penetration (see Figure 9) only slightly decreases with increasing injection pressure, the vapour penetration (see Figure 10) rises significantly, deeming the liquid/gas phase momentum transfer an influential process. The macroscopic liquid length is thought to be predominantly affected by air entrainment (or turbulent mixing) $(4,76)$. As the injection rate increases, so does the turbulent mixing, which continues to deliver energy that can break up the droplets around the same axial location.

The microscopic processes of the break up however do change with increasing injection pressures. Crua et al in (78) shows that the initial stages of injection are different between injection pressures. It is shown that at low injection pressures, surface tension is strong which allows slow but large droplet ligaments to be introduced. At higher injection pressures, break up forces exceed surface tension and 
429 fast and small droplet-like ligaments exit the nozzle. Since the injection rate and velocities are reduced

430 at lower pressures, less inertia is passed onto the vapor phase resulting in their slower progression.

431 Like in section 5.3.1, Figure 9 shows the comparison between the liquid penetrations of the raw DoE 432 optimised setup, the refined setup and the ECN test data. The reasons for the difference between the 433 DoE optimised setup and the refined setup have been described in the previous sections and apply here 434 as well. The liquid penetration of the refined setup shows good average liquid penetrations for all three 435 conditions and a comparable response of the absolute value to increasing injection pressures.

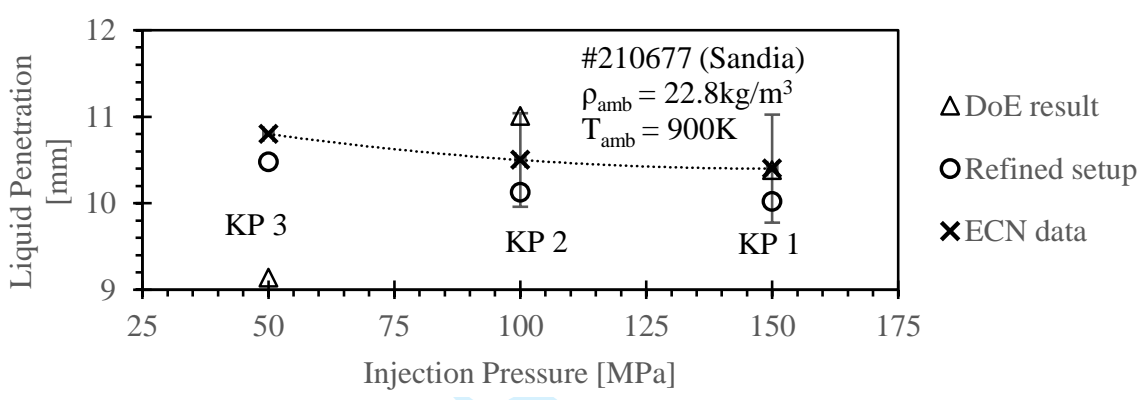

437 Figure 9: Simulated and experimental liquid penetration over injection pressure of KPs 1 - 3 under constant charge 438 density and temperature conditions

439 The refined setups vapor penetration (see Figure 10) of key points 1 and 2 are well captured throughout.

440 It proved to be difficult to appropriately adjust the vapor penetration of KP 5. This indicates that there 441 is merit for some further investigation into the gas/liquid momentum transfer at lower injection 442 pressures in future work.

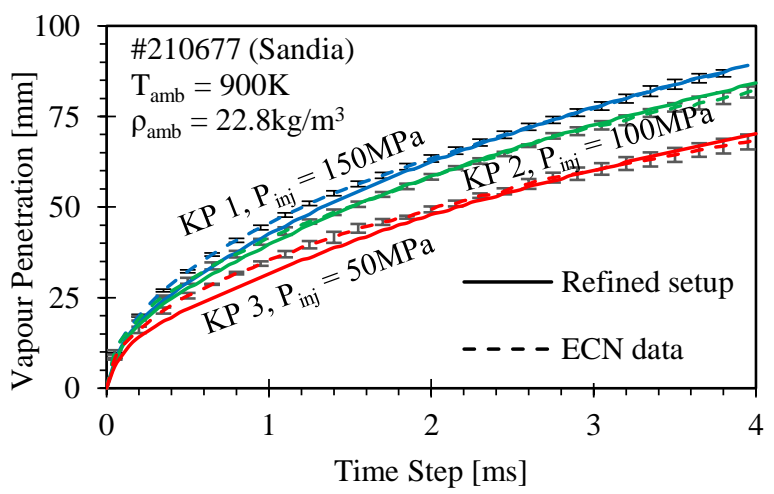

$444 \quad$ Figure 10: Simulated vs experimental vapour penetration of three injection pressure cases (KP 1 - 3) over the 445 duration of $4 \mathrm{~ms}$ under constant charge density and temperature conditions 
446 To increase confidence in the simulated mixture preparation, the radial mass fraction and gas phase 447 temperature distributions at three plume cross sections and axial mass fraction along the centreline of 448 the plume are compared to available experimental data captured at a steady state time interval. The 449 results are shown in Figure 11. In all metrics, the simulations perform well and, where available, lie 450 within the stated experimental error.
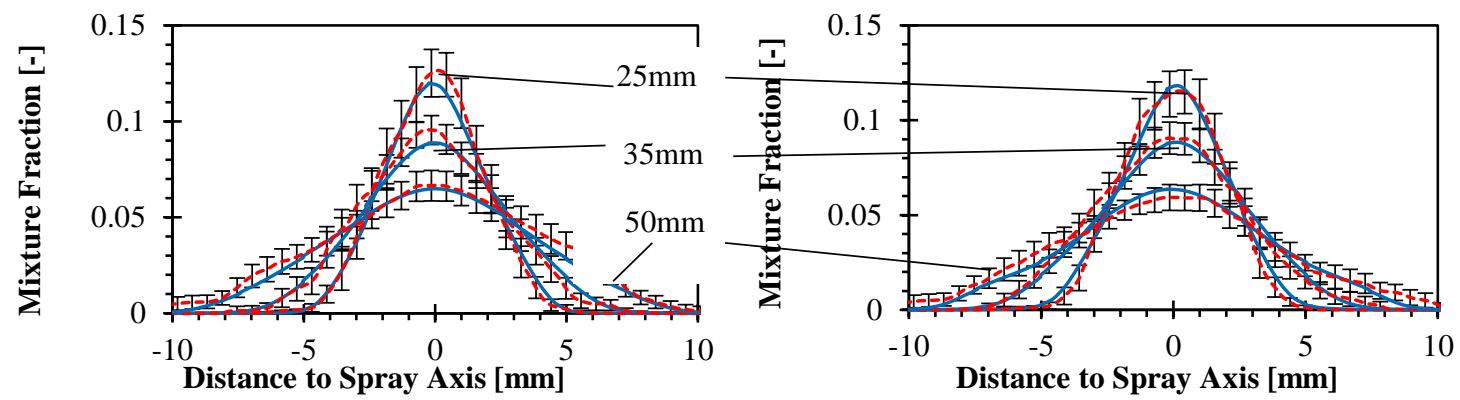

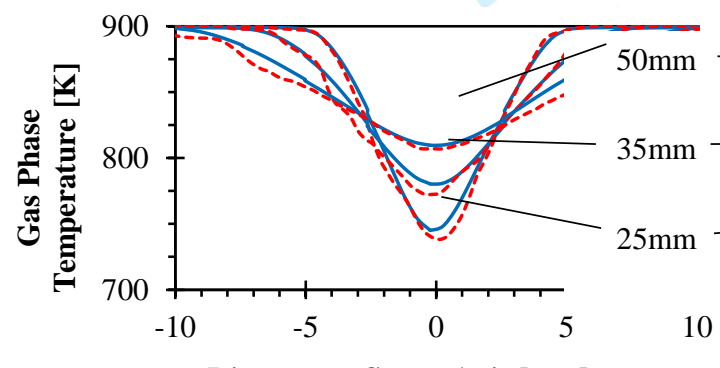

Distance to Spray Axis [mm]

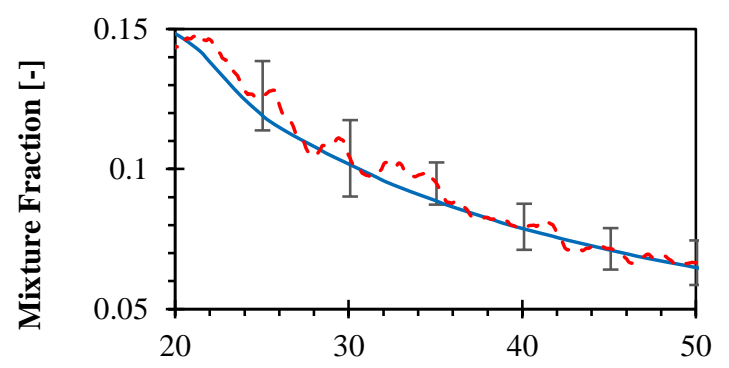

Axial Distance to Nozzle Exit [mm]

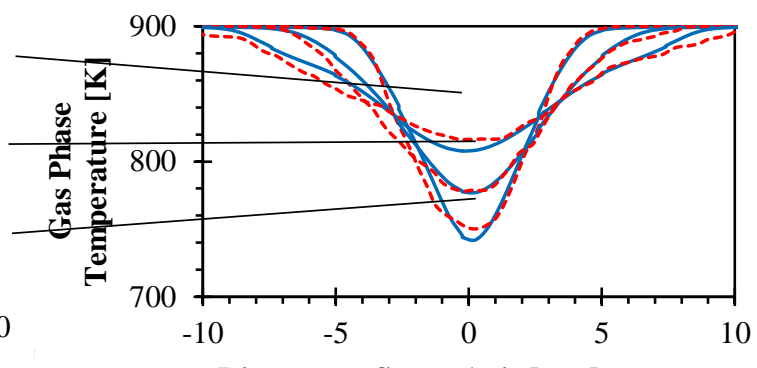

Distance to Spray Axis [mm]

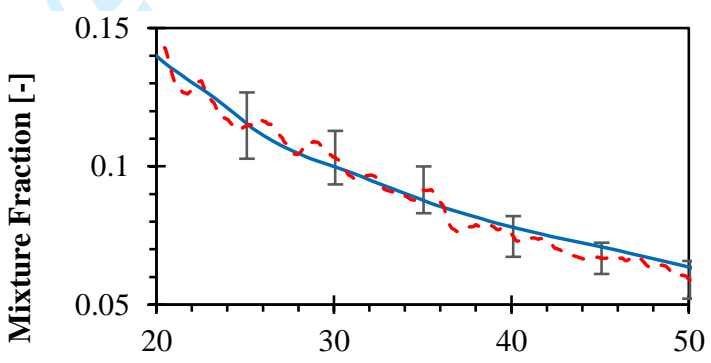

Axial Distance to Nozzle Exit [mm]

Figure 11: Comparison of radial mass fraction and gas phase temperature distribution at 25, 35 and $50 \mathrm{~mm}$ at $4 \mathrm{~ms}$

$\left(1^{\text {st }}\right.$ and $2^{\text {nd }}$ row) and centre axis mass fraction distribution at $3.2 \mathrm{~ms}\left(3^{\text {rd }}\right.$ row) between ECN test data (77) (red, dotted) and simulation (blue, solid) (KP2, left column and KP3, right column)

Figure 12 shows the accumulated droplet size probability distribution function (PDF) at three locations in the spray core across the simulated injection duration. It shows that the droplet shrinking of KP1 is initially significantly slower than for KP3 but is completed at approximately the same liquid length. 


\section{$478 \quad 6 \quad$ Conclusions}

479 Reliable simulations for in-cylinder processes are important to support adoption of increasingly 480 digitalised development processes in the automotive industry. Various virtual engineering tools exist to 481 reduce the dependency on expensive prototyping and testbed iterations, however still struggle either 482 with physical accuracy (RANS) or with high computational effort (LES \& DNS). With increasing 483 computational power, approaches like DNS and LES have become more affordable, but only show their 484 superiority over RANS in microscopic and simplified research-oriented environments or development 485 of more radical research concepts.

486 This work is dedicated to addressing RANS' main weakness, its heavy tuning dependency, while 487 preserving its main strength, the relative computational simplicity. It is shown that with appropriate 488 "clever" tuning, RANS can deliver excellent results for industrially relevant metrics like vapour and 489 liquid penetration as well as species mass fraction and temperatures in a time efficient manner which is 490 of paramount importance when the design of real devices is under consideration. A novel methodology 491 is presented where a DoE approach and subsequent automated optimisation have led to find simulation 492 setups, which can match multiple metrics of interest at five varying ECN Spray A operating conditions 493 in $\sim 2 \mathrm{hrs}$ per simulation. To the best of our knowledge, this is the first time that this reverse engineering 494 approach was conducted by running 100 simulations at related key points, defining the RMSE of each 495 of the simulation towards experimental comparison data and then using and automated optimiser to 496 minimise the error and show which combination of constants would produce a matching simulation. 497 This approach can only overcome the status of curve fitting by a investigating the used simulation 498 constants along with the respective physical conditions as a coherent picture. Like this, the following 499 findings were deduced:

500 1. The constant of dissipation $\mathrm{C}_{2}$ in the standard $\mathrm{k}-\varepsilon$ model, the drag scaling coefficient $\mathrm{A}_{\text {drag }}$, the 501 primary breakup time scale $\mathrm{B}_{1}$ and the initial droplet sizes are the key tuning parameters. It was 502 required to tune these to match vapour and liquid penetration as well as radial and axial 503 distributions of mass fraction and gas temperature at all conditions. 
2. The stochastic process models of all conditions confirm the known sensitivity of liquid and vapor penetration error towards a change of $\mathrm{C}_{2}$ and $\mathrm{B}_{1}$. The novel finding here however is that the distinct minima's, which represent lower RMSE's, settle for the similar value regardless of boundary condition. This suggests that although the simulations are highly sensitive to these two parameters, once their optimal value is found, they may remain unchanged for further operating conditions.

5103 . The drag scaling factor $\mathrm{A}_{\text {drag, }}$, which is crucial for liquid/gas phase momentum transfer, is highly sensitive towards changing chamber operating conditions, especially charge density and injection pressures.

4. The initial droplet sizes are a key simulation parameter and are highly sensitive towards injection pressures and charge densities.

The findings in the points above allow for the questions defined in the introduction to be addressed.

1. A study of recent literature suggests that liquid fuel may still be treated with classical evaporation equations even if the ambient conditions fall under the supercritical regime. The reason for this is the thermal inertia and rapid disintegration of droplets which breakup and evaporate the droplets before they reach supercritical conditions. This would solidify the claim that the conditions in this work are indeed subcritical and therefore permit the used traditional sub models.

2. Previous work and our approach here covered a large range of combinations of simulation constants in a selected set of sub models and we found no indication that the various conditions could have a potential simulation setup in common. Highlighting that the ECN Spray A is a simplified spray injection case, we assume it would only make it even more unlikely to find a single setup to match various real diesel injection conditions.

3. However, by comparing the DoE-derived simulation setups, we did identify some simulation constants which were robust to changing boundary conditions and others that had to be altered to match the condition. Most importantly, the sensitivity or robustness of the value of a constant could be traced back to its original physical expression. 
531

4. Point 3 indicates that there is then the potential to pre-define the simulation constants based on the prevailing boundary conditions.

The study shown here forms the basis to a subsequent investigation using these settings to develop the tabulation for $\sim 30$ reacting Spray A variations that will be presented in a future publication. Our most recent efforts on an optical single cylinder and a standard production engine (both small-bore direct injected light duty Diesel engines with swirl and multi hole injectors) using the tabulation only required small changes in the turbulence coefficients to show good agreement with a range of experimental data (79). A long-term objective of the project is the adoption of the tabulation into an algorithm that can auto-tune simulations based on input boundary conditions.

\section{Acknowledgements}

The authors would like to acknowledge the high-quality experiments conducted by Cyril Crua and his team at the University of Brighton and the participants of the ECN, particularly the Sandia National Laboratories and CMT Valencia. We would further like to thank Ricardo VECTIS for the free licenses and support by Evgeniy Shapiro, Nick Tiney and Irufan Ahmed. Assistance for the DoE software $\eta \mathrm{Cal}$ was provided by Justin Seabrook. The authors would also like to thank the UK's Engineering and Physical Science Research Council support through the grant EP/P012744/1 and EP/S001824/1.

\section{References}

1. Bardi M, Payri R, Malbec LM, Bruneaux G, Pickett LM, Manin J, et al. Engine Combustion Network: Comparison of Spray Development, Vaporization and Combustion in Different Combustion Vessels. 2012;22(10):807-42.

2. Meijer M, Somers B, Johnson J, Naber J, Lee S-Y, Malbec LM, et al. Engine Combustion Network $(\mathrm{ECN})$ : Characterization and Comparison of Boundary Conditions for different Combustion Vessels. Atomization and Sprays. 2012;22(9):777-806.

3. Pickett LM, Genzale CL, Bruneaux G, Malbec L-M, Hermant L, Christiansen C, et al. Comparison of Diesel Spray Combustion in Different High-Temperature, High-Pressure Facilities. SAE International Journal of Engines. 2010;3(2):156-81.

4. Siebers DL. Liquid-Phase Fuel Penetration in Diesel Sprays. SAE International; 1998.

5. Yeh CN, Kamimoto T, Kobori S, Kosaka H. 2-D Imaging of Fuel Vapor Concentration in a Diesel Spray via Exciplex-Based Fluorescence Technique. 1993-10-01: SAE International; 1993.

6. Kamimoto T, Yokota H, Kobayashi H. Effect of High Pressure Injection on Soot Formation Processes in a Rapid Compression Machine to Simulate Diesel Flames. 1987-09-01: SAE International; 1987. 
7. Espey C, Dec JE. The Effect of TDC Temperature and Density on the Liquid-Phase Fuel Penetration in a D. I. Diesel Engine*. 1995-10-01: SAE International; 1995.

8. Browne KR, Partridge IM, Greeves G. Fuel Property Effects on Fuel/Air Mixing in an Experimental Diesel Engine. 1986-02-01: SAE International; 1986.

9. Poursadegh F, Bibik O, Yraguen B, Genzale CL. A multispectral, extinction-based diagnostic for drop sizing in optically dense diesel sprays. International Journal of Engine Research. 2019:1468087419866034.

10. Manin J, Bardi M, Pickett LM, Payri R. Boundary condition and fuel composition effects on injection processes of high-pressure sprays at the microscopic level. International Journal of Multiphase Flow. 2016;83:267-78.

11. Payri R, Viera JP, Gopalakrishnan V, Szymkowicz PG. The effect of nozzle geometry over the evaporative spray formation for three different fuels. Fuel. 2017;188:645-60.

12. Bardi M, Payri R, Malbec LMC, Bruneaux G, Pickett LM, Manin J, et al. Engine Combustion Network: Comparison of Spray Development, Vaporization and Combustion in Different Combustion Vessels. Atomization and Spray. 2012;22(10):807-42.

13. Benajes J, Payri R, Bardi M, Martí-Aldaraví P. Experimental characterization of diesel ignition and lift-off length using a single-hole ECN injector. Applied Thermal Engineering. 2013;58(12):554-63.

14. Payri R, García-Oliver JM, Bardi M, Manin J. Fuel temperature influence on diesel sprays in inert and reacting conditions. Applied Thermal Engineering. 2012;35:185-95.

15. Siebers DL, Higgins B, Pickett L. Flame Lift-Off on Direct-Injection Diesel Fuel Jets: Oxygen Concentration Effects. 2002-03-04: SAE International; 2002.

16. Siebers DL, Higgins B. Flame Lift-Off on Direct-Injection Diesel Sprays Under Quiescent Conditions. SAE International; 2001.

17. Higgins B, Siebers DL. Measurement of the Flame Lift-Off Location on DI Diesel Sprays Using OH Chemiluminescence. SAE International; 2001.

18. Pickett LM, Siebers DL, Idicheria CA. Relationship Between Ignition Processes and the Lift-Off Length of Diesel Fuel Jets. 2005-10-24: SAE International; 2005.

19. Payri R, Salvador FJ, Manin J, Viera A. Diesel ignition delay and lift-off length through different methodologies using a multi-hole injector. Applied Energy. 2016;162:541-50.

20. Payri R, Viera JP, Gopalakrishnan V, Szymkowicz PG. The effect of nozzle geometry over ignition delay and flame lift-off of reacting direct-injection sprays for three different fuels. Fuel. 2017;199:76-90.

21. Payri R, Viera JP, Pei Y, Som S. Experimental and numerical study of lift-off length and ignition delay of a two-component diesel surrogate. Fuel. 2015;158:957-67.

22. Pickett LM, Siebers DL. Fuel Effects on Soot Processes of Fuel Jets at DI Diesel Conditions. 200310-27: SAE International; 2003.

23. Siebers DL, Pickett LM, editors. Injection Pressure and Orifice Diameter Effects on Soot in DI Diesel Fuel Jets. Thermo- and Fluid Dynamic Processes in Diesel Engines 2; 2004 2004//; Berlin, Heidelberg: Springer Berlin Heidelberg.

24. Pickett LM, Siebers DL. Non-Sooting, Low Flame Temperature Mixing-Controlled DI Diesel Combustion. 2004-03-08: SAE International; 2004.

25. Pickett LM, Siebers DL. Soot in diesel fuel jets: effects of ambient temperature, ambient density, and injection pressure. Combustion and Flame. 2004;138(1):114-35.

26. Idicheria CA, Pickett LM. Soot Formation in Diesel Combustion under High-EGR Conditions. SAE International; 2005.

27. Pandurangi SS, Bolla M, Wright YM, Boulouchos K, Skeen SA, Manin J, et al. Onset and progression of soot in high-pressure $n$-dodecane sprays under diesel engine conditions. International Journal of Engine Research. 2016;18(5-6):436-52.

28. Yeh C-N, Kamimoto T, Kobori S, Kosaka H. 2-D Imaging of Fuel Vapor Concentration in a Diesel Spray via Exciplex-Based Fluorescence Technique. 1993-10-01: SAE International; 1993.

29. Aubagnac-Karkar D, Michel J-B, Colin O, Darabiha N. Combustion and soot modelling of a highpressure and high-temperature Dodecane spray. International Journal of Engine Research. 2017;19(4):434-48. 
30. Bolla M, Gudmundsson T, Wright YM, Boulouchos K. Simulations of Diesel Sprays Using the Conditional Moment Closure Model. SAE International Journal of Engines: SAE International; 2013. p. 1249-61.

31. Blomberg CK, Zeugin L, Pandurangi SS, Bolla M, Boulouchos K, Wright YM. Modeling Split Injections of ECN "Spray A" Using a Conditional Moment Closure Combustion Model with RANS and LES. SAE International Journal of Engines. 2016;9(4):2107-19.

32. Pei Y, Hawkes ER, Kook S, Goldin GM, Lu T. Modelling n-dodecane spray and combustion with the transported probability density function method. Combustion and Flame. 2015;162(5):200619.

33. Bhattacharjee S, Haworth DC. Simulations of transient n-heptane and n-dodecane spray flames under engine-relevant conditions using a transported PDF method. Combustion and Flame. 2013;160(10):2083-102.

34. Pei Y, Hawkes ER, Bolla M, Kook S, Goldin GM, Yang Y, et al. An analysis of the structure of an n-dodecane spray flame using TPDF modelling. Combustion and Flame. 2016;168:420-35.

35. Varna A, Wehrfritz A, R. Hawkes E, J. Cleary M, Lucchini T, D'Errico G, et al. Application of a multiple mapping conditioning mixing model to ECN Spray A. Proceedings of the Combustion Institute. 2018.

36. Pei Y, Davis MJ, Pickett LM, Som S. Engine Combustion Network (ECN): Global sensitivity analysis of Spray A for different combustion vessels. Combustion and Flame. 2015;162(6):233747.

37. Kundu P, Pei Y, Wang M, Mandhapati R, Som S. Evaluation of Turbulence-Chemistry interaction under Diesel Engine Conditions with Multi-Flamelet RIF Model. Atomization and Spray. 2014;24(9):779-800.

38. Desantes JM, García-Oliver JM, Novella R, Pérez-Sánchez EJ. Application of an unsteady flamelet model in a RANS framework for spray A simulation. Applied Thermal Engineering. 2017;117:5064.

39. Pei Y, Som S, Pomraning E, Senecal PK, Skeen SA, Manin J, et al. Large eddy simulation of a reacting spray flame with multiple realizations under compression ignition engine conditions. Combustion and Flame. 2015;162(12):4442-55.

40. Pei Y, Som S, Kundu P, Goldin GM. Large Eddy Simulation of a Reacting Spray Flame under Diesel Engine Conditions. 2015-09-01: SAE International; 2015.

41. Pei Y, Hu B, Som S. Large-Eddy Simulation of an n-Dodecane Spray Flame Under Different Ambient Oxygen Conditions. Journal of Energy Resources Technology. 2016;138(3):032205--10.

42. Wehrfritz A, Vuorinen V, Kaario O, Larmi M. Large Eddy Simulation of High-Velocity Fuel Sprays: Studying Mesh Resolution And Breakup Model Effects for Spray A. 2013;23(5):41942.

43. Kahila H, Wehrfritz A, Kaario O, Ghaderi Masouleh M, Maes N, Somers B, et al. Large-eddy simulation on the influence of injection pressure in reacting Spray A. Combustion and Flame. 2018;191:142-59.

44. Xue Q, Som S, Senecal PK, Pomraning E. Large Eddy Simulation of Fuel-Spray Under NonReacting IC Engine Conditions. Atomization and Spray. 2013;23(10):925-55.

45. Gong C, Jangi M, Bai X-S. Large eddy simulation of n-Dodecane spray combustion in a high pressure combustion vessel. Applied Energy. 2014;136:373-81.

46. Jones WP, Marquis AJ, Vogiatzaki K. Large-eddy simulation of spray combustion in a gas turbine combustor. Combustion and Flame. 2014;161(1):222-39.

47. Kaario OT, Vuorinen V, Kahila H, Im HG, Larmi M. The effect of fuel on high velocity evaporating fuel sprays: Large-Eddy simulation of Spray A with various fuels. International Journal of Engine Research. 2019:1468087419854235.

48. Ihme M, Ma PC, Bravo L. Large eddy simulations of diesel-fuel injection and auto-ignition at transcritical conditions. International Journal of Engine Research. 2018;20(1):58-68.

49. Pérez-Sánchez EJ, García-Oliver JMM, Novella R, Pastor JM. Understanding the diesel-like spray characteristics applying a flamelet-based combustion model and detailed large eddy simulations. International Journal of Engine Research. 2019:1468087419864469.

50. Lee CH, Wang Y, Reitz RD. CFD Simulation of Diesel Spray over a Wide Range of Ambient Gas Densities Using an Improved Gas Jet Spray Model. 2011;21(7):591-609. 
51. Vijayraghavan Iyengar S, Rutland C. Effect of Physical Properties on Spray Models. SAE International; 2013.

52. Wang H, Reitz RD, Yao M. Comparison of Diesel Combustion CFD Models and Evaluation of the Effects of Model Constants. SAE International; 2012.

53. Nsikane DM, Mustafa K, Ward A, Morgan R, Mason D, Heikal M. Statistical Approach on Visualizing Multi-Variable Interactions in a Hybrid Breakup Model under ECN Spray Conditions. SAE International Journal of Engines. 2017;10(5).

54. Nsikane D, Vogiatzaki K, Morgan R, Heikal M. Assessment of the performance of conventional spray models under high pressure and high temperature conditions using a "Design of Experiments" approach. ICLASS 2018, 14th Triennial International Conference on Liquid Atomization and Spray Systems; Chicago, USA2018.

55. Nsikane D, Vogiatzaki K, Morgan R. Predictive Engine Simulations based on a novel DoE/RANS approach with coefficient tabulation. IMechE, Fuel Systems-Engines; London2018.

56. Network EC. Data Search Utility https://ecn.sandia.gov/ecn-data-search/: Sandia National Laboratories 2016 [

57. Engine Combustion Network. "Spray A" and "Spray B" Operating Conditions https://ecn.sandia.gov/diesel-spray-combustion/target-condition/spray-ab/: Engine Combustion Network; 2016 [

58. Bellan J. Supercritical (and subcritical) fluid behavior and modeling: drops, streams, shear and mixing layers, jets and sprays. Progress in Energy and Combustion Science. 2000;26(4):329-66.

59. Dahms RN. Understanding the breakdown of classic two-phase theory and spray atomization at engine-relevant conditions. Physics of Fluids. 2016;28(4):042108.

60. Chauveau C, Dagaut P, GÖKalp I, Cathonnet M. Vaporization And Oxidation Of Liquid Fuel Droplets At High Temperature And High Pressure: Application To N-alkanes And Vegetable Oil Methyl Esters Au - Morin * , Céline. Combustion Science and Technology. 2004;176(4):499529.

61. Falgout Z, Rahm M, Wang Z, Linne M. Evidence for supercritical mixing layers in the ECN Spray A. Proceedings of the Combustion Institute. 2015;35(2):1579-86.

62. Falgout Z, Rahm M, Sedarsky D, Linne M. Gas/fuel jet interfaces under high pressures and temperatures. Fuel. 2016;168:14-21.

63. Wensing M, Vogel T, Götz G. Transition of diesel spray to a supercritical state under engine conditions. International Journal of Engine Research. 2015;17(1):108-19.

64. Crua C, Manin J, Pickett LM. On the transcritical mixing of fuels at diesel engine conditions. Fuel. 2017;208:535-48.

65. Chung WT, Ma PC, Ihme M. Examination of diesel spray combustion in supercritical ambient fluid using large-eddy simulations. International Journal of Engine Research. 2019:1468087419868388.

66. Li G, Sapsford SM, Morgan RE. CFD Simulation of DI Diesel Truck Engine Combustion Using VECTIS. SAE International; 2000.

67. Jones WP, Launder BE. The prediction of laminarization with a two-equation model of turbulence. International Journal of Heat and Mass Transfer. 1972;15(2):301-14.

68. Lefebvre A. Atomization and Sprays: Taylor \& Francis; 1988.

69. Beale JC. Modeling fuel injection using Kelvin-Helmholtz/Rayleigh-Taylor hybrid atomization model in KIVA-3V: University of Wisconsin--Madison; 1999.

70. Putnam A. Integratable Form of Droplet Drag Coefficient. J. Am. Rocket Soc.; 1961. p. 14674798.

71. D.B. S. The Combustion of Liquid Fuels. 4th Symposium (International) on Combustion; Baltimore: Williams \& Wilkins; 1953. p. pp. 847-64.

72. Chin JSaL, A.H. The Role of the Heat-up Period in Fuel Drop Evaporation. Int J Turbo Jet Engines. 1985; vol. 2,:pp. 315-25.

73. Sacks J, Welch WJ, Mitchell TJ, Wynn HP. Design and Analysis of Computer Experiments. Statist Sci. 1989;4(4):409-23.

74. Som S, Senecal, P.K., Pomraning, E. Comparison of RANS and LES Turbulence Models against Constant Volume Diesel Experiments. ILASS Americas, 24th Annual Conference on Liquid Atomization and Spray Systems; San Antonio, TX2012. 
727

728

729

730

731

732

733

734

735

736

737

738

739

740

741

742

743

744

745

746

747

748

749

750

751

752

753

754

75. Magnotti GM, Genzale CL. Detailed assessment of diesel spray atomization models using visible and X-ray extinction measurements. International Journal of Multiphase Flow. 2017;97:33-45.

76. Naber JD, Siebers DL. Effects of Gas Density and Vaporization on Penetration and Dispersion of Diesel Sprays. SAE International; 1996.

77. Pickett LM, Manin J, Genzale CL, Siebers DL, Musculus MPB, Idicheria CA. Relationship Between Diesel Fuel Spray Vapor Penetration/Dispersion and Local Fuel Mixture Fraction. SAE International Journal of Engines. 2011;4(1):764-99.

78. Crua C, Heikal MR, Gold MR. Microscopic imaging of the initial stage of diesel spray formation. Fuel. 2015;157:140-50.

79. Nsikane D, Vogiatzaki K, Morgan R, Mustafa K, Ward A. Predictive CFD Auto-Tuning Approach For In-Cylinder EU6 LDD DI Engine. 2019-09-09: SAE International; 2019.

80. Borman GL, Johnson JH. Unsteady Vaporization Histories and Trajectories of Fuel Drops Injected into Swirling Air. SAE International; 1962.

81. Chin JS, Lefebvre AH. The Role of the Heat-up Period in Fuel Drop Evaporation. International Journal of Turbo and Jet Engines1985. p. 315.

\section{Appendix}

\section{Mathematical Background of Sub Models}

The following is an overview of the governing equations for an individual droplet moving in a carrier fluid. The two-phase flow is considered a dispersed liquid phase in the continuous gas phase based on the Lagrangian approach

\section{Turbulence Model}

The turbulent motion in this work is modelled using the Standard k- $\varepsilon$ turbulence model. A full description of all terms would be lengthy but can be found in Jones et al in (67). Here we focus on the two terms which had a major impact on the quality of the simulation. The terms $\mathrm{C}_{1}$ and $\mathrm{C}_{2}$ are responsible for scaling the dissipation rate of the turbulent kinetic energy. A higher $\mathrm{C}_{2}$ increases dissipating effects and consequently increases the diffusion of the gas phase. The transport equation for the turbulent kinetic energy (Eq 2) and its dissipation rate (Eq 3) in the standard k- $\varepsilon$ model are:

$$
\frac{\partial(\rho k)}{\partial t}+\frac{\partial\left(\rho U_{i} k\right)}{\partial x_{i}}=\frac{\partial}{\partial x_{i}}\left[\mu^{\prime} \frac{\partial k}{\partial x_{i}}\right]+G-\rho \epsilon
$$




$$
\frac{\partial(\rho \epsilon)}{\partial t}+\frac{\partial\left(\rho U_{i} \epsilon\right)}{\partial x_{i}}=\frac{\partial}{\partial x_{i}}\left[\mu^{\prime} \frac{\partial \epsilon}{\partial x_{i}}\right]+\frac{\epsilon}{k}\left(C_{1} G-C_{2} \rho \epsilon+C_{3} \rho k \frac{\partial U_{i}}{\partial x_{i}}\right)
$$

755 Initial trials varying the turbulence dissipation coefficients showed a strong sensitivity of vapour 756 penetration. For this reason, they have been selected for closer investigation.

757

758

759

760

761

762

763

764

765

766

767

768

769

770

771

772

773

774

\section{Droplet introduction}

The droplets are introduced as a chain of spherical blobs that are grouped in parcels of droplets with similar attributes and as such treated with the underlying equations. The diameters of these initial droplets can either be defined by the user or left to be calculated by various initial droplet size correlations. In this work, the authors have selected a user defined droplet introduction typically known as "Table introduction". This list of droplet sizes vs probability is flexible and introduces no new variables. The disadvantage is that it does not consider any nozzle flow characteristics or charge conditions. To further simplify the droplet introduction, only a single droplet size is introduced. Multiple impact studies conducted throughout the study showed that there was no apparent benefit of applying more complex droplet introduction methods and distributions.

\section{Momentum conservation}

The momentum equation for a droplet of mass $m_{d}$ is described by Newton's Second Law (Eq 4) in which $C_{d}$ is the aerodynamic drag coefficient, $A_{f}$ is the projected area of the droplet in moving direction, $A_{\text {drag }}$ is a user defined tuning coefficient, $\rho_{g}$ is the density of the surrounding gas and the relative velocities between the droplets and the gas $\vec{U}$. This momentum contribution is then added into the energy and momentum conservation equations as a source term. The initial screening of simulations constants highlighted $A_{\text {drag }}$ as highly influential, so it has been added to the list of coefficients to be investigated with more detail.

$$
m_{d} \frac{d \vec{V}}{d t}=\frac{1}{2} C_{d} A_{f} A_{d r a g} \rho_{g}|\vec{U}| \vec{U}
$$


775 The drag coefficient $C_{d}$ is calculated by the Putnam model, which is expressed as shown in Eq 5. The 776 model defines the $C_{d}$ to be that of a sphere for the case the droplet Reynolds number are $>1000$. Based 777 on this, it has been hypothesized that a value of $0<A_{\text {drag }} \leq 1$ in Eq 5 is physically reasonable as it 778 accounts for the droplet drag coefficient for deformed droplets. Although values above 1 are 779 theoretically possible, they would not be physically justifiable.

$$
C_{d}= \begin{cases}\frac{24}{R e_{d}}\left(1+\frac{1}{6} R e_{d}^{2 / 3}\right) & \text { for } R e_{d} \leq 1000 \\ 0.424 & \text { for } R e_{d}>1000\end{cases}
$$

780

781

\section{Mass and energy conservation}

During the evaporation of the droplet in a spray, it experiences simultaneous heat and mass transfer processes. By means of convection and conduction, the heat from the surrounding gas is transported into the droplet surface. The fuel vapour is returned to the gas stream via convection and diffusion. A detailed recollection of the underlaying equations would be lengthy but can be found in the original papers $(71,80,81)$.

\section{Spray break-up}

\section{Primary breakup modelling}

In this work, an industry standard hybrid break-up model named KH-RT model (69) is used. It is based on the Kelvin-Helmholtz (KH) and Rayleigh-Taylor (RT) instability theory. A parent droplet with the radius $r$ breaks up into new child droplets with the radius $r_{c}$ following Eq 6 . The tuning constant $B_{0}$ is a multiplier to linearly alter the size of the child droplet. The characteristic breakup time $\tau_{K H}$ is calculated as shown in Eq 7, with $\Omega_{K H}$ and $\Lambda_{K H}$ being the maximum wave growth rate and its corresponding wave length. For the sake of brevity, the latter two parameters are not further elaborated. These equations show that $B_{0}$ and $B_{1}$ are the tuning factors responsible for the rate at which the parent droplet shrinks and defines the size of the child droplet as shown in Eq 8. These two coefficients are classic user 
797 definable input parameters that have shown to impact the simulated results and have therefore been 798 added to the list of investigated constants.

$$
\begin{gathered}
r_{c}=B_{0} \Lambda_{K H} \\
\tau_{K H}=\frac{3.788 B_{1} r}{\Omega_{K H} \Lambda_{K H}} \\
\frac{d r}{d t}=\frac{r-r_{c}}{\tau_{K H}}
\end{gathered}
$$$$
\text { Eq } 7
$$$$
\text { Eq } 8
$$

799 The switch between when primary and secondary breakup equations is defined by the breakup length $800 L_{b}$ in the Levich model. It is calculated as shown in Eq 9. $A_{b u}$ and $B_{b u}$ are user tuning constants. The 801 original authors recommended a value of 5.5 and 0 respectively. While $A_{b u}$ scales the break up length 802 based on the nozzle size and therefore appears to scale to some real boundary condition, $B_{b u}$ being a 803 simple addition is arguably arbitrary. Therefore, $A_{b u}$ but not $B_{b u}$ have been added to the list of 804 coefficients to be investigated.

$$
L_{b}=A_{b u} D_{n} \sqrt{\frac{\rho_{l}}{\rho_{g}}}+B_{b u}
$$

805

806 807

\section{Secondary breakup modelling}

The RT model is then used in conjunction with KH to predict the secondary breakup of the droplets. The RT model predicts instabilities on the surface of the droplets that grow until a certain characteristic breakup time when the drop finally breaks up. Once waves begin to grow on the surface of the droplet, the wave growth time $\Omega_{R T}$ is tracked. This time is then compared to the breakup time. Usually, $C_{R T}$ is a tuning factor and that kept at unity. 


$$
\tau_{R T}=\frac{C_{R T}}{\Omega_{R T}}
$$

811 If the RT waves have been growing for a time greater than the breakup time, the drop is assumed to

812 break up. The approximated diameter $D_{d}$ of this stable droplet size is influenced by $C_{3}$. The correlation

813 is shown in Eq 11. Both $C_{R T}$ and $C_{3}$ are influential parameters and will be investigated in more detail.

$$
\frac{d D_{d}}{d t}=-\frac{D_{d}-2 \pi C_{3}}{\tau_{R T} K_{R T}}
$$

